\title{
Tipologías actuales de los trabajadores sociales en España ${ }^{1}$
}

\author{
Current typologies of social workers in Spain \\ Juan Jesús ViscARRET GARRO \\ Universidad Pública de Navarra, España \\ juanj.viscarret@unavarra.es \\ Alberto BALLESTERO IZQUIERDO \\ Universidad Pública de Navarra, España \\ alberto.ballestero@unavarra.es \\ Francisco IDARETA GOLDARACENA \\ Universidad Pública de Navarra, España \\ francisco.idareta@unavarra.es \\ María Jesús ÚRIz PEMÁN \\ Universidad Pública de Navarra, España \\ ivan@unavarra.es
}

Recibido: 16/11/2015

Revisado: 16/12/2015

Aceptado: 09/05/2016

Disponible on line: 01/07/2016

\section{Resumen}

El objetivo del artículo es definir y explicar los tipos de profesionales del Trabajo Social existentes en España mediante una investigación descriptiva, cuantitativa y tipológica. Esta primera aproximación puede servir para iniciar la reflexión sobre la organización profesional del Trabajo Social en España y para identificar las características que definen su labor profesional. Los resultados muestran la existencia de doce tipos de profesionales del Trabajo Social en España.

Palabras clave: Trabajo Social, ámbitos profesionales, problemáticas profesionales, funciones profesionales, tipologías, salidas profesionales.

\begin{abstract}
The aim of the article is to define and explain the current types of social work professionals in Spain, through descriptive, quantitative and typological research. This first investigation may help to instigate reflection on the professional organization of social work in Spain and to identify the features that define work in the profession. The results reveal the existence of twelve types of social work professionals in Spain.

Keywords: Social Work, professional fields, professional duties, typologies, professional issues.
\end{abstract}

Referencia normalizada» Viscarret Garro, J. J., Ballestero Izquierdo, A., Idareta Goldaracena F. y Úriz Pemán, M.J. (2016): «Tipologías actuales de los trabajadores sociales en España». Cuadernos de Trabajo Social, 29(2): 239-262.

Sumario: Introducción. 1. Metodología. 2. Resultados. 3. Conclusiones. 4. Referencias bibliográficas.

\section{Introducción}

El desempeño profesional de los profesionales del Trabajo Social en España es cada vez más heterogéneo y diversificado, como producto de la mayor complejidad, pluralidad y diversidad de las problemáticas a las que debe hacer frente la profesión. Esta es una representación colectiva bastante extendida, donde parece imperar la lógica de la fragmentación, donde la profesión parece difuminarse en una infinidad de particularidades. En esta línea, Hernández (2004, p. 176) señala que los ámbitos de intervención y los mo-

${ }^{1}$ Este artículo refleja algunos de los resultados obtenidos en el proyecto de investigación FFI 2013465309, financiado por el Ministerio de Economía y Competitividad del Gobierno de España. 
dos de intervenir «son tan múltiples que explican la dificultad en el ámbito científico de fijar-determinar el objeto (común) de reflexión, lo que ha llevado históricamente a un constante cuestionamiento de la identidad del profesional del trabajo social» como un oficio técnico adherido a una serie de normas profesionales (Salazar, 2006) y portando una serie de valores que identifican a la profesión (Webb, 2015).

A nuestro entender, son tres los elementos decisivos que determinan la heterogeneidad de la ejecución profesional (praxis) de los trabajadores sociales: los ámbitos de intervención profesional, las problemáticas reales con las que trabajan cotidianamente $y$ las funciones que concretan la acción profesional cotidiana. La investigación realizada pretende caracterizar qué peso tienen cada uno de estos elementos a la hora de determinar una u otra forma de hacer Trabajo Social. En la concreción de estos elementos hemos tomado como base lo especificado en el Libro Blanco de Trabajo Social. Con motivo de la adaptación de los estudios de Trabajo Social al Espacio Europeo de Educación Superior, se realizó en España un estudio pormenorizado de la legislación europea, nacional y autonómica, ámbitos de intervención y problemáticas que deben desempeñar las profesionales del Trabajo Social. Dicho estudio y análisis fue llevado a cabo por profesionales del Trabajo Social (Consejo General del Trabajo Social) y por personas del ámbito universitario y cristalizó en la realización del Libro Blanco de Trabajo Social (Vázquez, 2004) donde, entre otros aspectos, se realiza un análisis del perfil profesional de los profesionales del Trabajo Social.

En primer lugar, nos referiremos a los ámbitos de intervención profesional. Los ámbitos de intervención los entendemos como los espacios de práctica profesional que requieren de la presencia e intervención de los trabajadores sociales en la mejora del sistema social (Fernández, 2009, p. 350). El Libro Blanco de Trabajo Social (Vázquez, 2004, p. 140) recoge que el ámbito profesional hace referencia a los espacios delimitados por la organización institucional de los servicios en los que opera el trabajador social y por el marco programático y operativo en el que se concreta y desarrolla su labor. Por lo tanto, los ámbitos de intervención son los espacios que la profesión define como espacios de desarrollo profesional, que van cambiando y evolucionando en el tiem- po producto de la creciente diversidad/complejidad de las necesidades sociales. Los ámbitos de intervención del Trabajo Social son dinámicos porque intentan responder a problemáticas sociales cada vez más complejas. Estas problemáticas surgen como resultado de la tensión entre las necesidades y los derechos, la diversidad de expectativas sociales y un conjunto de diferentes dificultades para alcanzarlas en un escenario de incertidumbre, desigualdad y posibilidades concretas de desafiliación (Carballeda, 2010). A su vez, generan una gran cantidad de situaciones heterogéneas a las que es necesario atender y dar respuesta, sea cual sea el ámbito profesional en el que se desempeñe la labor profesional. Un profesional del Trabajo Social de un ámbito determinado puede trabajar con problemáticas concretas, propias de su ámbito profesional y otras no tan obvias, debido al complejo proceso de las problemáticas sociales que atiende.

Además de la complejidad de ámbitos y de problemáticas, los profesionales del Trabajo Social desarrollan en su praxis toda una serie de funciones profesionales. Todas las profesiones intentan redefinir y garantizar unas funciones y unos conocimientos especializados como fundamento de su realización profesional. El concepto de función surge de la naturaleza misma del proceso social del trabajo y permite identificar la aportación que hace a la sociedad una profesión, describiendo su finalidad y estableciendo sus límites. En el Libro Blanco de Trabajo Social (Vázquez, 2004) se mencionan, tras realizar un análisis pormenorizado del perfil profesional de los profesionales del Trabajo Social, las funciones laborales que le competen al trabajador social en España.

De esta manera, ámbitos de intervención, problemáticas que se atienden y funciones profesionales que se desempeñan se convierten en variables interesantes para un análisis científico que concrete experiencias profesionales diversas dentro de la misma profesión del Trabajo Social. Con este fin, hemos realizado un estudio descriptivo de carácter cuantitativo y tipológico con el objetivo de caracterizar los diferentes tipos de profesionales del Trabajo Social existentes en España, teniendo en cuenta el peso de dichas variables (ámbito, función, problemática que se atiende) en el conjunto de su desempeño profesional. El acercamiento al conocimiento de esta tipología profesional tiene un objetivo reflexivo en varios niveles: las tipologías sugieren qué elementos de los 
mencionados caracterizan y diferencian una práctica profesional del Trabajo Social de otra, la existencia de tipos de profesionales diferentes nos hablará de la heterogeneidad de la praxis profesional $\mathrm{y}$ de qué peso tienen unos perfiles profesionales sobre otros, permite evidenciar y observar qué objetos de intervención son los característicos de la profesión y hacia donde se desplaza la misma. También es útil para identificar aspectos que pueden ser abordados en el currículo formativo y que pueden servir para orientar propuestas docentes (Grado, Máster, Doctorado).

Con las tipologías se pretende identificar, en primera instancia, clasificaciones de una realidad, como la de la práctica profesional del Trabajo Social en España que, en sí misma, es ya heterogénea y compleja. Pero también, y sobre todo, en segunda instancia, dar forma y estructurar dichos tipos. La elaboración de objetos sociológicos bajo la morfología del tipo nos permite no solo una mayor elaboración y precisión conceptual, sino también una mejor comprensión, aprehensión de la identidad del hecho social y, en su caso, de su estructuración e incluso introducidos en teorías taxonómicas o correlacionales generales, la posibilidad de un cierto grado de explicación que trasciende la función clasificatoria que se les atribuye.

\section{Metodología}

\subsection{Instrumento}

El cuestionario utilizado está basado en el elaborado por la Dra. Ain en Estados Unidos, que fue revisado y aprobado - según explica en su tesis doctoral - por los doctores Philip J. Boyle, Director Adjunto del Hastings Institute (Vancouver, Canadá), Vicepresidente y Editor Jefe del Park Ridge Center (Chicago, Illinois); Jonathan D. Moreno, Catedrático de Bioética en la Universidad de Virginia y Director del Centro de Bioética; y Bárbara Ann Lieberman, experta en estadística y analista de programas del Ministerio de Sanidad y Servicios Sociales de Estados Unidos. Además, el estudio también fue sometido a la evaluación de un tribunal de expertos: los doctores Norman Linzer y Charles Auerbach, catedráticos de Trabajo Social en Yeshiva University (Nueva York) y Elaine Congress, catedrática de Servicios Sociales y Directora de los programas de posgrado y doctorado en Fordham University (Nueva York) (Ain, 2001).
El cuestionario fue traducido, contextualizado, adaptado al ámbito español y publicado por miembros del grupo Efimec de la Universidad Pública de Navarra (Uriz, Ballestero \& Urien, 2007, pp. 119-130) y está dividido en siete grandes bloques: datos personales, datos profesionales, código de ética, cuestiones éticas, dilemas éticos, dilemas éticos en su trabajo diario y formación en ética. Para el presente artículo se han utilizado las preguntas referidas a los ámbitos de intervención profesional (18 ítems), las funciones profesionales desempeñadas en su trabajo diario (17 ítems) y las principales problemáticas (16 ítems) con las que trabajan. Todas ellas compuestas por una escala Likert de cuatro opciones (Nada, Poco, Algo, Bastante).

\subsection{Procedimiento}

La metodología utilizada en la investigación ha sido cuantitativa (basada en el envío de un cuestionario por correo postal). La población objeto de estudio es la compuesta por el colectivo de trabajadores sociales colegiados en España en activo (Consejo General del Trabajo Social de España). Para la realización del estudio se contó con el acceso al Banco de Datos del Consejo General del Trabajo Social en España en el que figuraban un total de 8.505 profesionales (2009).

La matriz de datos la compone una muestra de 700 trabajadores sociales. La unidad muestral es aleatoria y nominativa. Aplicando la fórmula del error muestral para poblaciones finitas, significa que para un nivel de confianza de dos sigmas $(95,5$ por ciento), donde $\mathrm{p}=\mathrm{q}=0,50$, donde el universo de referencia es de 8.505 profesionales y la muestra que se obtiene $n=700$, el error muestral es de $\pm 3,5$ por ciento para datos globales. La tasa de respuesta real fue del 20 por ciento (1.523 cuestionarios útiles/7.963 cuestionarios enviados (descontados los devueltos)*100). De los cuestionarios útiles se realizó un proceso de revisión y depuración de los datos con el objetivo garantizar la calidad de la información obtenida, (buscando inconsistencias, evaluando la no respuesta, etc.), obteniendo la muestra final necesaria para el estudio. El trabajo de campo se realizó entre octubre y diciembre del año 2009.

\subsection{Caracterización de la muestra}

Han sido 700 los profesionales que forman parte de la muestra (n). La distribución por sexos de los profesionales del Trabajo Social en España 
está fuertemente feminizada: el 91 por ciento son mujeres y el 9 por ciento, hombres, lo cual se ajusta a las diversas investigaciones realizadas en torno a este colectivo. En cuanto a la distribución por edades, el 40 por ciento tiene entre $31 \mathrm{y}$ 40 años y el 30 por ciento corresponde a la franja entre 41 y 50 años, mientras el 17 por ciento tiene entre 20 y 30 años y el 13 por ciento tiene más de 50 años.

En cuanto a la experiencia profesional, el 38 por ciento tiene entre 6 y 15 años de experiencia como trabajadora o trabajador social; el 28 por ciento, entre 16 y 25 años de experiencia profesional; el 24 por ciento, hasta 5 años de experiencia, y sólo el 10 por ciento tiene más de 25 años de experiencia.

\subsection{Análisis estadísticos}

Para el proceso analítico se ha empleado la versión número 18 del programa SPSS y se ha realizado un análisis factorial exploratorio, donde interaccionan diversas variables asociadas en la investigación, así como un análisis de conglomerados (cluster analysis) para definir los grupos de interés en función de dichas variables. El análisis factorial es un método de análisis multivariante que intenta reducir, a través de un modelo lineal, un conjunto extenso de variables observables a un número menor de variables hipotéticas, denominadas factores (Kim y Mueller, 1978, p. 191). Se ha utilizado este método debido a que el número de variables observadas en torno a funciones, ámbitos y problemáticas era extenso (51). Se ha optado por un AFE debido a que no se conocía a priori el número de factores, siendo la aplicación empírica la que determinaría su número. Para observar la correlación entre las diversas variables se han realizado varios indicadores de su asociación como el Test de esfericidad de Barlett y la Medida de Adecuación a la Muestra KMO, obteniendo en ambos casos estadísticos favorables (KMO. 0,871 / Bartlett. Chicuadrado, 12498,543, Gl 1176, Sig, 0,000). Una vez determinada la viabilidad del AFE, se ha seleccionado el método de componentes principales como método más adecuado a la extracción de los factores. Una vez seleccionado el número de factores, se ha aplicado una rotación Varimax con el fin de minimizar el número de variables que tienen saturaciones altas en cada factor y de simplificar la interpretación de los factores. Esta reducción de variables era necesaria con el fin de poder realizar posteriormente una clasificación tipológica, mediante un análisis de clúster. Se ha realizado una fijación del porcentaje de varianza y se han tomado los factores que lo explican. Como señala Martínez Ramos (1984, p. 167), un aspecto fundamental a considerar en un análisis de cluster es que el número de variables no sea demasiado grande y que la unidad de medida sea la misma para todas las variables analizadas. Una vez formada la matriz de similaridad o de distancias entre individuos, se decidió por la técnica de agrupamiento a utilizar. En este caso se decidió utilizar la no jerárquica, debido a que los métodos jerárquicos tienen el inconveniente de ser más inestables y es difícil decidir cuántos grupos deben seleccionarse tras el análisis (Martínez Ramos, 1984, p. 165) y a que, según otros autores (Alcantud, 195, p. 81), este tipo de técnica se adapta mejor a estudios psicológicos y sociológicos con grandes conjuntos de datos. Además esta técnica permite corregir asignaciones incorrectas. La técnica utilizada para la validación de los conglomerados ha sido el análisis de varianza con el fin de conocer las diferencias que muestran las variables (factores en este caso) en cada uno de los clusters y el análisis discriminante, con objeto de descubrir el porcentaje de sujetos se encuentran correctamente asignados. El análisis discriminante se utiliza para analizar como un conjunto de individuos con unas determinadas características pueden clasificarse dentro de una serie de grupos definidos a priori (en este caso conglomerados), tratando de localizar cuáles son las características que los diferencian. Es decir, se pone a prueba su capacidad para predecir si un individuo, con unas determinadas características es clasificado correctamente por el modelo. Así, en el Anexo 1 se muestra un cruce de tablas entre los individuos pertenecientes a cada cluster y aquellos que están correctamente especificados, según el Análisis Discriminante. El estadístico resultante informa de una alta capacidad predictora en el conjunto del mismo ( 96,8 por ciento).

\section{Resultados}

Se realizó un análisis factorial con el fin de observar agrupamientos de variables y de reducir la complejidad del análisis. Se han tomado un total de 51 variables, las cuales preguntan a los profesionales - mediante una escala Likert de cuatro puntos - la ubicación en torno al desempeño de 
funciones, problemáticas sociales con las que trabajan y ámbito de intervención en el que desempeñan su labor profesional. Seleccionado el número de variables y después de aplicar una rotación Varimax, el resultado estadístico arroja un total de 12 factores, que explican el 65,4 por ciento de la varianza y que a continuación pasamos a describir (Medida Kaiser-Meyer-Olkin (KMO) de adecuación de muestreo. 0,871 / Prueba de esfericidad de Bartlett (Chi-cuadrado, 12498,543, Gl 1176, Sig, 0,000) (Véase Anexo 1).

- Factor 1. Inmigración/Racismo/Minorías. Agrupa las variables relacionadas con ámbitos de intervención y problemáticas relacionadas con Refugiados y Asilados, Minorías étnicas, Inmigración, Racismo, Marginados sin hogar, Emigrantes y Alojamiento.

- Factor 2. Adicciones/Delincuencia. Agrupa las variables relacionadas con ámbitos y problemáticas de intervención relacionadas con las adicciones (ludopatías, alcoholismo, drogadicción) y con el trabajo con reclusos y ex-reclusos.

- Factor 3. Infancia/Juventud/Educación/Familia. Agrupa las variables relacionadas con ámbitos y problemáticas de intervención relacionadas con infancia, juventud, problemas de integración escolar, centros escolares y familia.

- Factor 4. Dependencia y Salud. Agrupa las variables relacionadas con ámbitos de intervención y problemáticas relacionadas con personas con discapacidad, personas mayores, enfermos terminales, enfermos psiquiátricos no institucionalizados, salud mental y centros de salud y hospitales.

- Factor 5. Funciones de Gestión de Servicios Sociales y Política Social. Agrupa variables relacionadas exclusivamente con funciones profesionales como planificación de centros, organización, diseño e implantación de políticas sociales para crear o reajustar servicios, supervisión, coordinación de grupos, medios, servicios y recursos y la no atención directa a individuos.

- Factor 6. Exclusión social. Agrupa variables relacionadas con la atención a problemáticas relacionadas con la exclusión social (problemas económicos, desempleo, vivienda) y a funciones profesionales relacionadas con la Promoción e inserción social.

- Factor 7. Mujer. Reúne las variables relacionadas con la atención de problemáticas que tienen un claro factor de género (atención a la violencia contra las mujeres y el trabajo del ámbito de la prostitución) y con el área de intervención de mujer.

- Factor 8. Académico. Este factor aglomera exclusivamente funciones que tienen que ver con el desempeño docente e investigador.

- Factor 9. Comunitario. Este factor reúne exclusivamente funciones profesionales que tienen que ver directamente con la intervención comunitaria: prevención, planificación (diseño de proyectos y programas de intervención) y con la atención directa a grupos.

- Factor 10. Diagnóstico y evaluación de la intervención. Este factor asocia exclusivamente funciones profesionales relacionadas con la intervención profesional directa como el diagnóstico y la evaluación.

- Factor 11. Problemas conductuales e intervención familiar. Este factor agrupa únicamente problemáticas que tienen que ver con el comportamiento y la interacción de individuos, relacionadas con problemas conductuales individuales y con problemáticas de intervención familiar.

- Factor 12. Burocrático. Este factor aglutina una única función, la relacionada con las funciones administrativas y burocráticas no relacionadas directamente con el trabajo de intervención profesional.

\subsection{Análisis de conglomerados}

Una vez llevada a cabo esta reducción dimensional, se procedió a generar una clasificación tipológica de los profesionales según su posición factorial. Con ello se pretende observar si existen diferentes tipos profesionales, atendiendo a las problemáticas con las que trabajan diariamente, a las funciones que realizan y a los ámbitos de intervención en su práctica profesional diaria. Para ello, procedimos a la realización de un estudio de conglomerados no jerárquico ( $k$ medias) que comienza con una división del conjunto de datos en un numero $x$ de grupos, para ir afinando dicha clasificación en sucesivos pasos con el fin de reducir la distancia media entre cada elemento de un grupo y su centro. Se tuvieron en cuenta tres aspectos fundamentales para elegir las variables que se utilizaron, tal y como señala Martínez-Ramos (1984): que las variables estén inter-correlacionadas, que la unidad de medida sea la misma para todas las variables analizadas y que el número de variables no 


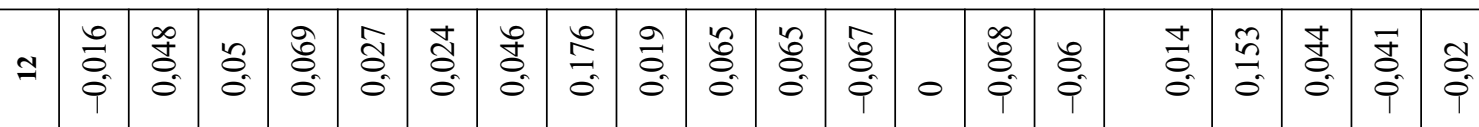

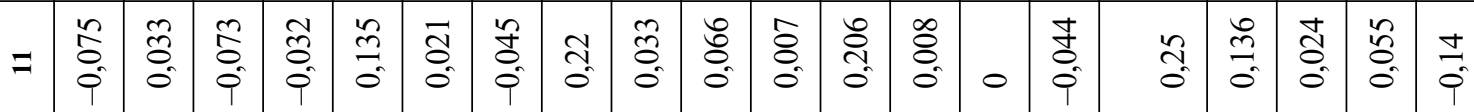

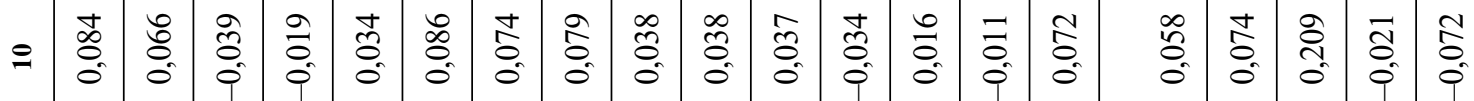

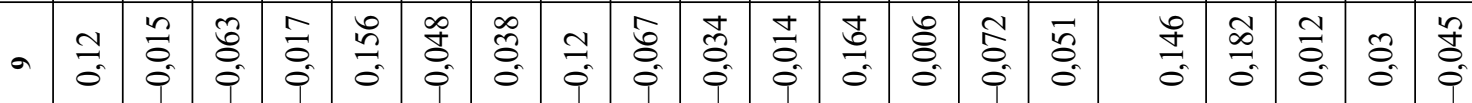

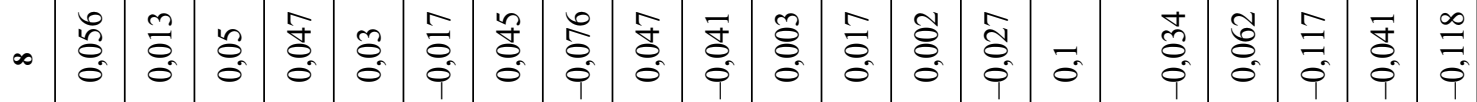

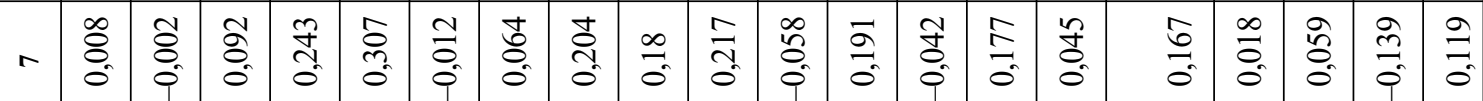

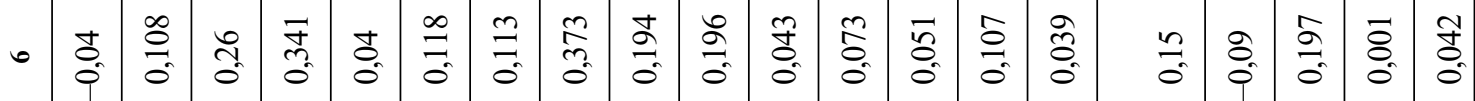

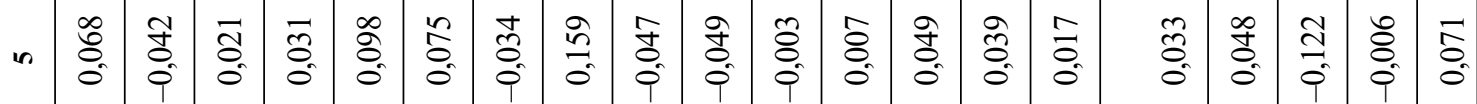

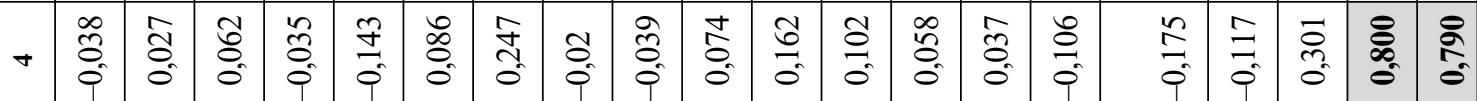

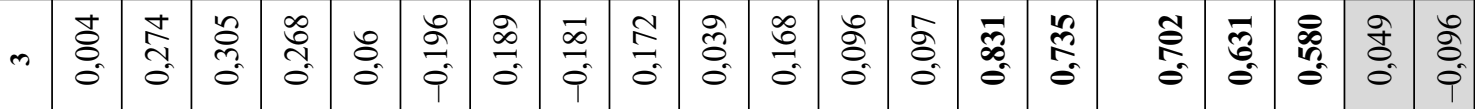

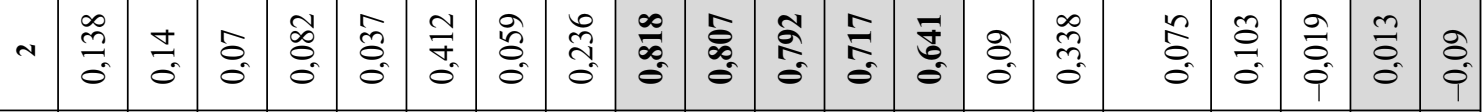

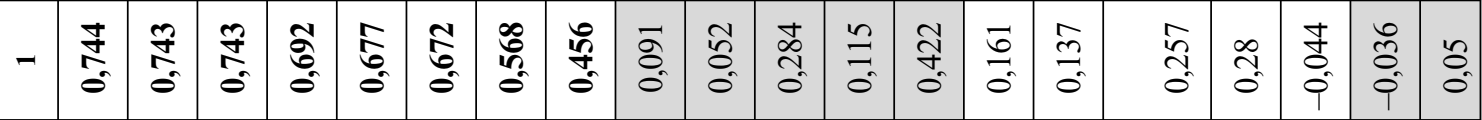

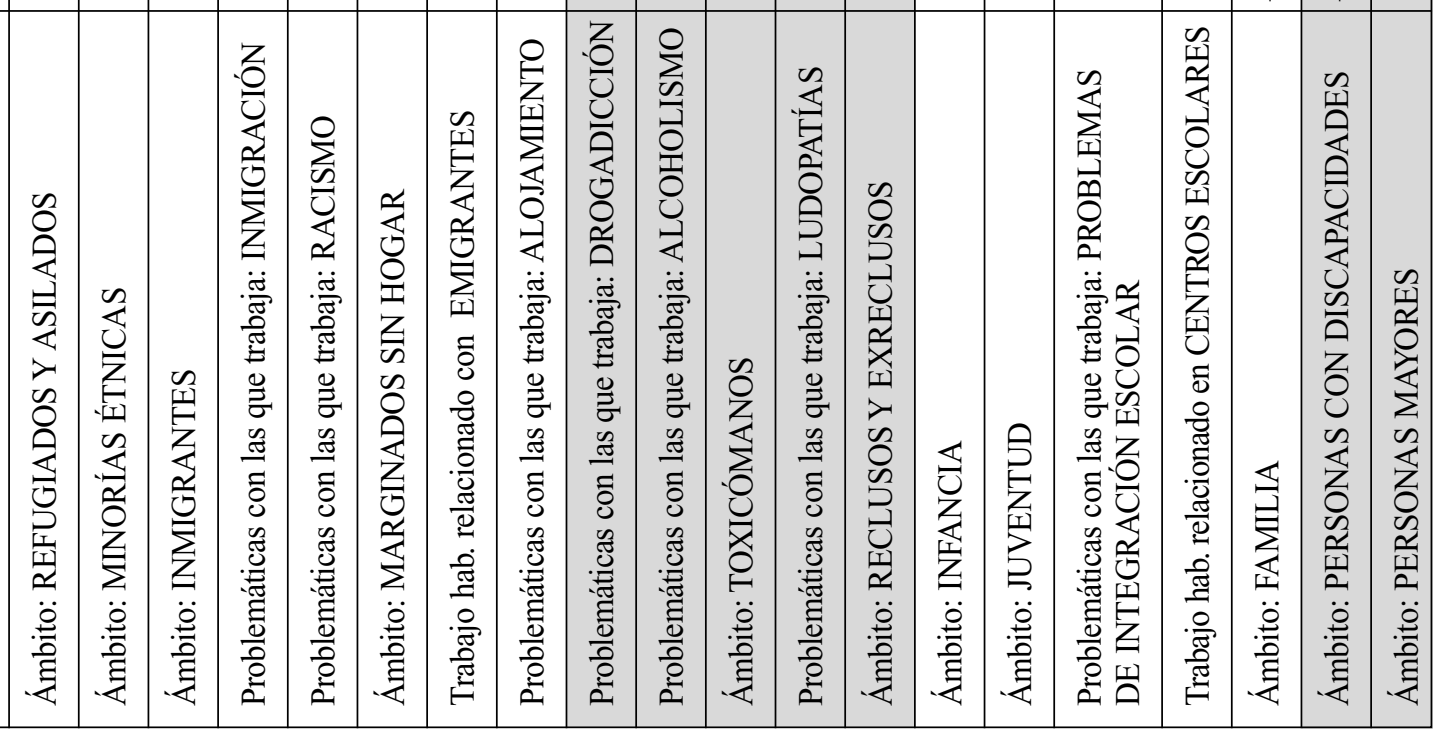




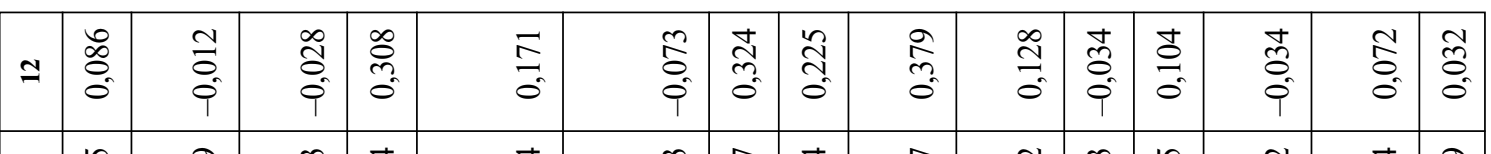

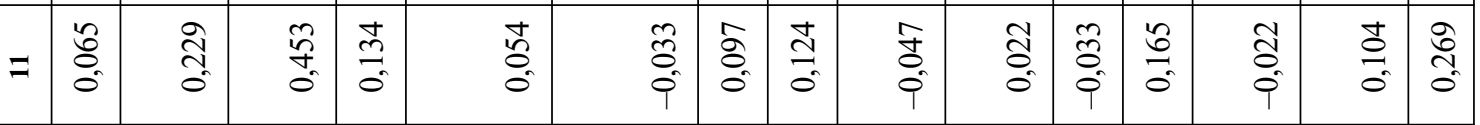

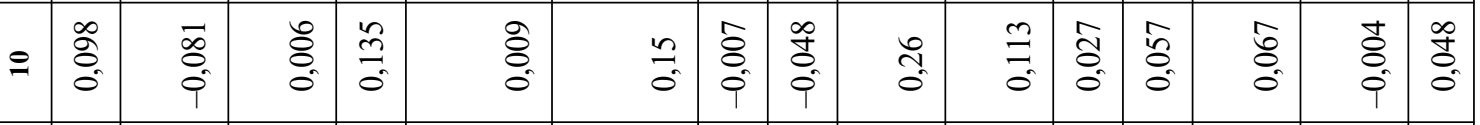

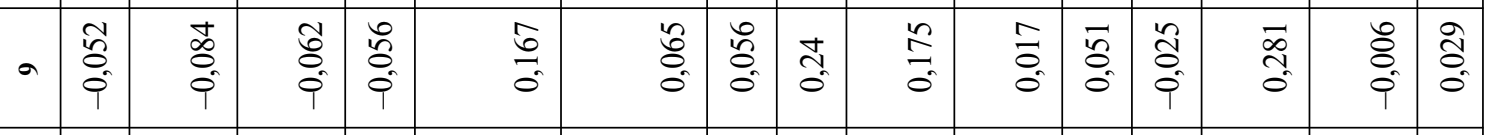

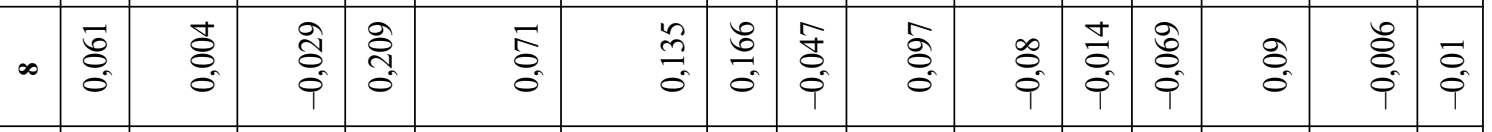

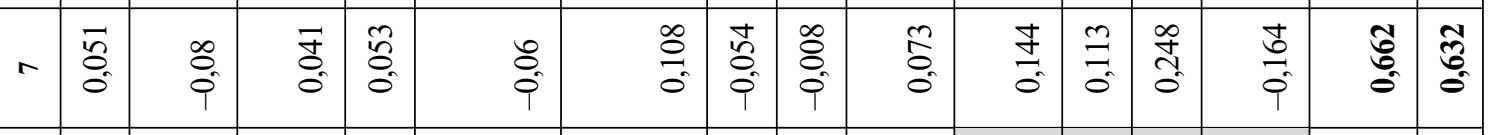

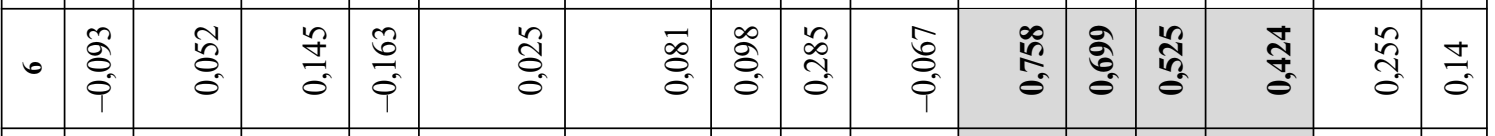

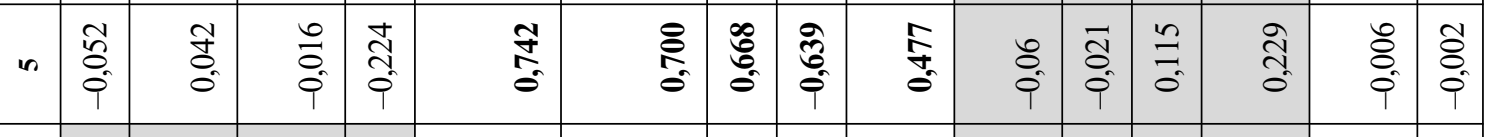

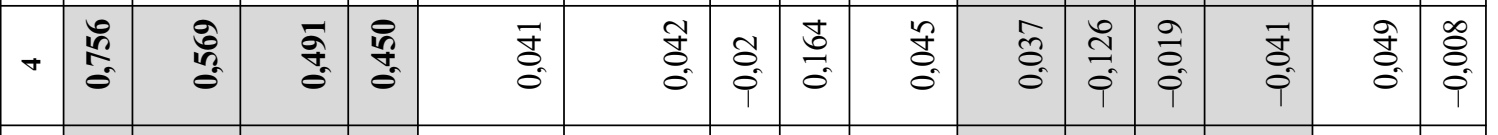

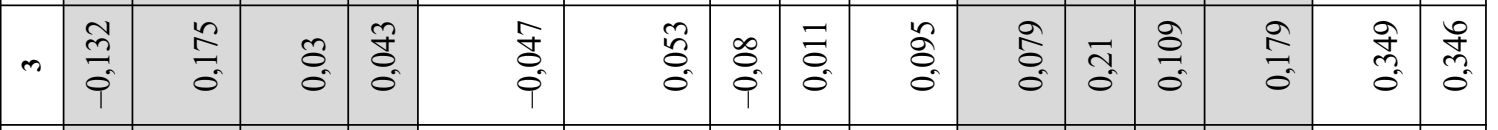

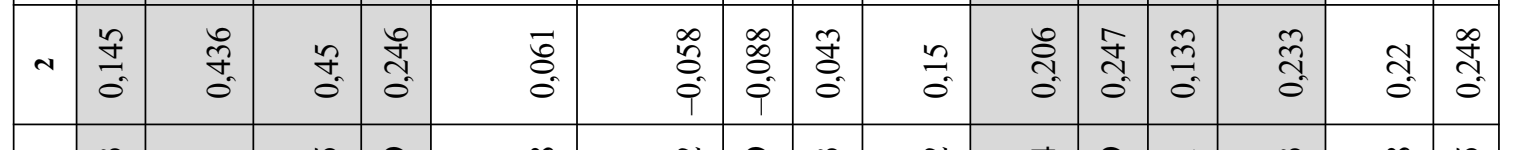

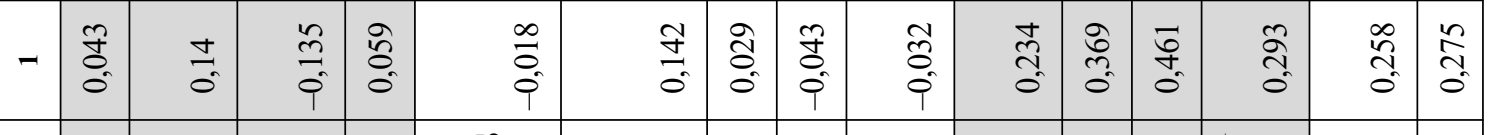

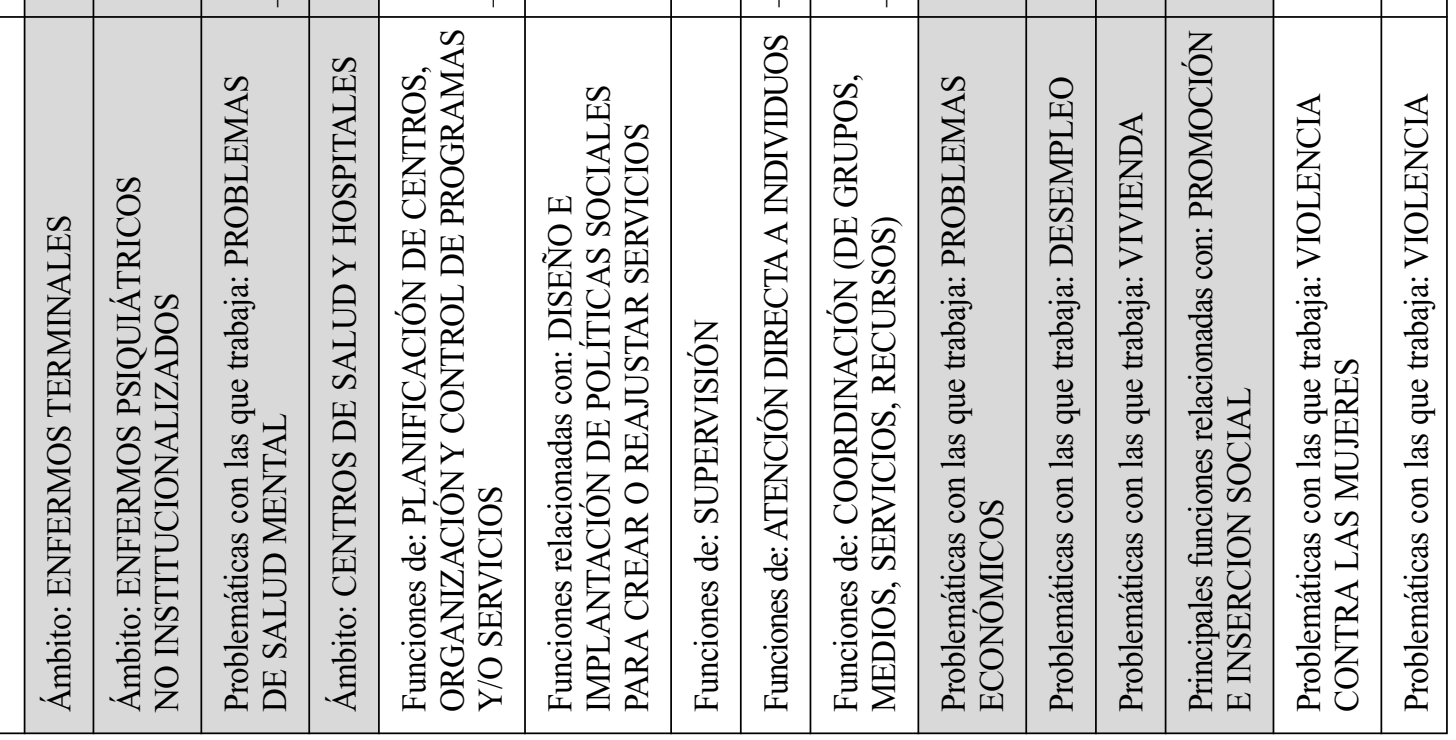




\begin{tabular}{|c|c|c|c|c|c|c|c|c|c|c|c|c|c|c|}
\hline$\simeq$ & в. & $\hat{\tilde{\delta}}$ & 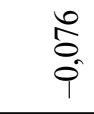 & \&্. & $\begin{array}{l}\stackrel{+}{0} \\
\stackrel{0}{0}\end{array}$ & $\frac{\cong}{\frac{1}{9}}$ & $\stackrel{0}{0}$ & तี & $\stackrel{2}{0}$ & $\hat{0}$ & $\frac{\pi}{0}$ & $\begin{array}{l}0 \\
0 \\
0 \\
0\end{array}$ & \begin{tabular}{l}
0 \\
\hdashline \\
0 \\
0
\end{tabular} & $\begin{array}{l}0 \\
: 0 \\
: 0\end{array}$ \\
\hline$=$ & $\stackrel{\infty}{0}$ & 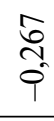 & $\stackrel{\infty}{8}$ & $\begin{array}{l}0 \\
0 \\
0\end{array}$ & $\frac{8}{0}$ & ஜे & $\begin{array}{l}\tilde{N} \\
\tilde{\sigma}\end{array}$ & $\stackrel{n}{=}$ & $\begin{array}{l}0 \\
\& \\
0 \\
0\end{array}$ & $\begin{array}{l}\bar{\sigma} \\
\dot{0}\end{array}$ & $\frac{\infty}{\stackrel{\infty}{0}}$ & $\underset{\overbrace{}}{\stackrel{\infty}{\sigma}}$ & ڤ్ & $\frac{\widetilde{\sigma}}{\tilde{\rho}}$ \\
\hline$\varrho$ & 0 & $\underset{0}{0}$ & $\begin{array}{l}\frac{d}{0} \\
0\end{array}$ & $\frac{\text { I }}{0}$ & $\begin{array}{l}\hat{\imath} \\
\hat{\varphi}\end{array}$ & $\underset{0}{\stackrel{+}{g}}$ & $\stackrel{\infty}{8}$ & $\begin{array}{l}\text { तે } \\
\text { ठิ }\end{array}$ & $\begin{array}{l}\stackrel{\Rightarrow}{0} \\
0\end{array}$ & $\frac{9}{\stackrel{t}{s}}$ & $\frac{0}{6}$ & $\stackrel{\widetilde{\Omega}}{0}$ & $\begin{array}{l}\tilde{\hat{n}} \\
\tilde{\sigma}\end{array}$ & $\bar{\sigma}$ \\
\hline$a$ & 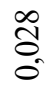 & $\frac{\sigma}{0}$ & 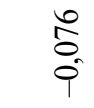 & $\begin{array}{l}\sqrt{0} \\
0\end{array}$ & $\begin{array}{l}\text { तె } \\
\text { ㅇ }\end{array}$ & $\overrightarrow{0}$ & $\frac{\tilde{N}}{\stackrel{\rho}{\sigma}}$ & : & $\begin{array}{l}\text { ర్. } \\
\stackrel{0}{\circ}\end{array}$ & 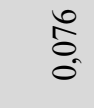 & $\begin{array}{l}\text { הె } \\
\text { ô }\end{array}$ & $\begin{array}{l}\overrightarrow{0} \\
0\end{array}$ & है. & $\stackrel{\cong}{\exists}$ \\
\hline$\infty$ & $\stackrel{+}{0}$ & $\frac{\hat{n}}{0}$ & $\frac{\overline{0}}{\stackrel{0}{0}}$ & 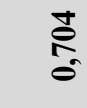 & $\begin{array}{l}8 \\
20 \\
0 \\
0\end{array}$ & $\frac{0}{8}$ & $\frac{n}{\tilde{\sigma}}$ & $\begin{array}{l}\text { ठे } \\
\text { ণे }\end{array}$ & $\begin{array}{l}4 \\
\text { t. } \\
0\end{array}$ & $\begin{array}{l}\frac{8}{0} \\
0\end{array}$ & fo & 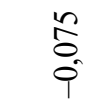 & $\begin{array}{l}2 \\
\stackrel{0}{0} \\
\stackrel{1}{0}\end{array}$ & $\frac{\vec{D}}{i}$ \\
\hline$r$ & $\begin{array}{l}\text { तू } \\
\text { مू } \\
0\end{array}$ & ๙ू. & $\begin{array}{l}\text { S } \\
8 \\
0\end{array}$ & $\frac{n}{0}$ & $\frac{\hat{m}}{\hat{9}}$ & $\frac{\Delta}{\tilde{\sigma}}$ & $\begin{array}{l}\overline{8} \\
0\end{array}$ & $\hat{n}$ & $\begin{array}{l}\text { I } \\
\stackrel{0}{0}\end{array}$ & $\begin{array}{l}\infty \\
8 \\
0 \\
0\end{array}$ & $\begin{array}{l}\text { రె } \\
\stackrel{0}{0}\end{array}$ & $\frac{N}{0}$ & $\begin{array}{l}\infty \\
\infty \\
\sim \\
0\end{array}$ & $\begin{array}{l}0 \\
\stackrel{0}{0} \\
0\end{array}$ \\
\hline 6 & $\stackrel{0}{0}$ & $\begin{array}{l}\text { ते } \\
\text { กิ }\end{array}$ & $\begin{array}{c}\text { ma } \\
\hat{0} \\
0\end{array}$ & $\frac{d}{\stackrel{d}{0}}$ & $\frac{\square}{0}$ & $\begin{array}{l}\equiv \\
\overline{0}\end{array}$ & $\frac{n}{8}$ & $\hat{o}_{0}^{\infty}$ & $\stackrel{\infty}{8}$ & $\begin{array}{l}\stackrel{\infty}{\varrho} \\
\stackrel{0}{0}\end{array}$ & ڤ્ડ & $\begin{array}{l}\infty \\
\stackrel{8}{8} \\
0\end{array}$ & $\begin{array}{l}\text { Fे } \\
\text { ma }\end{array}$ & है \\
\hline in & $\hat{\sigma}_{0}$ & $\begin{array}{l}\text { tu } \\
0 \\
0\end{array}$ & $\frac{8}{0}$ & $\frac{\mathcal{I}}{0^{\circ}}$ & $\frac{ \pm}{\stackrel{ \pm}{0}}$ & $\frac{\vec{m}}{\overrightarrow{0}}$ & $\frac{2}{0}$ & $\begin{array}{l}\text { ț } \\
\text { N. }\end{array}$ & $\underset{\sigma}{\stackrel{\sigma}{\sigma}}$ & $\hat{o}$ & 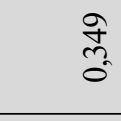 & $\stackrel{m}{0}$ & $\frac{\vec{m}}{i}$ & 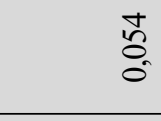 \\
\hline 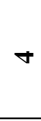 & $\begin{array}{l}\hat{0} \\
\hat{9}\end{array}$ & $\underset{\sim}{\infty}$ & $\hat{0}$ & ڤิ & $\frac{\Delta}{0}$ & $\begin{array}{l}8 \\
8 \\
0\end{array}$ & हे & $\begin{array}{l}\hat{\sigma} \\
\hat{0} \\
0\end{array}$ & $\begin{array}{l}n \\
0 \\
0\end{array}$ & $\begin{array}{l}0 \\
0 \\
0 \\
0\end{array}$ & $\begin{array}{l}\infty \\
\stackrel{2}{0} \\
\stackrel{0}{0}\end{array}$ & $\begin{array}{l}\stackrel{ \pm}{=} \\
\overrightarrow{0}\end{array}$ & $\stackrel{n}{\stackrel{2}{0}}$ & $\begin{array}{l}\frac{8}{0} \\
0\end{array}$ \\
\hline$m$ & in & 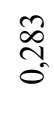 & $\begin{array}{l}\bar{\sigma} \\
0 \\
0\end{array}$ & $\begin{array}{l}\approx \\
0 \\
0\end{array}$ & তু & $\begin{array}{l}\text { dे } \\
\stackrel{0}{\circ}\end{array}$ & $\begin{array}{l}\tilde{0} \\
\hat{0} \\
0\end{array}$ & 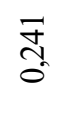 & $\begin{array}{l}+ \\
8 \\
0 \\
0\end{array}$ & $\frac{\mathbb{I}}{0}$ & $\frac{8}{0}$ & $\frac{\infty}{\infty}$ & $\begin{array}{l}\infty \\
m_{0} \\
{ }_{0}^{2}\end{array}$ & $\stackrel{\tilde{0}}{0}$ \\
\hline$N$ & $\stackrel{\mathcal{F}}{\circ}$ & $\frac{\tilde{n}}{0}$ & $\begin{array}{l}0 \\
0 \\
0\end{array}$ & ठ̊. & $\hat{n}$ & $\widetilde{\delta}$ & $\overrightarrow{\mathbf{s}}$ & 离 & 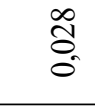 & $\begin{array}{l}\hat{\partial} \\
\ddot{0}\end{array}$ & $\underset{0}{\stackrel{d}{d}}$ & 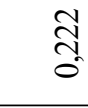 & $\begin{array}{l}\text { त̃ } \\
\text { ֶ̊ }\end{array}$ & $\begin{array}{l}\text { ठี } \\
\text { ठ }\end{array}$ \\
\hline- & $\begin{array}{l}\infty \\
\omega_{n}^{n} \\
\hat{\sigma}^{2}\end{array}$ & స్ & है. & $\begin{array}{l}\text { } \\
\tilde{8}\end{array}$ & ह̊ & $\begin{array}{l}\infty \\
\stackrel{0}{0}\end{array}$ & $\stackrel{8}{8}$ & $\begin{array}{l}\bar{\sigma} \\
0 \\
0\end{array}$ & $\begin{array}{l}\text { J } \\
0\end{array}$ & $\frac{8}{0}$ & $\frac{F}{0}$ & $\frac{a}{0}$ & $\begin{array}{l}n \\
\tilde{o} \\
0 \\
0\end{array}$ & $\begin{array}{l}\text { f } \\
0 \\
0\end{array}$ \\
\hline & 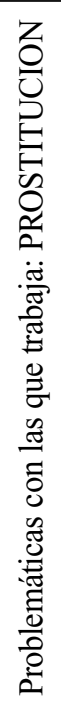 & 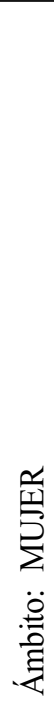 & 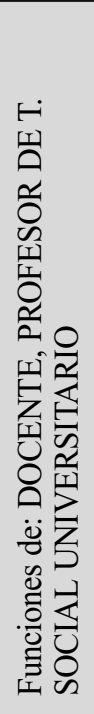 & 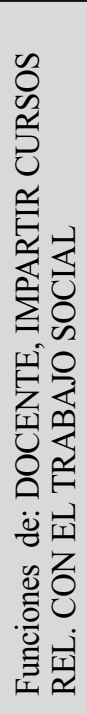 & 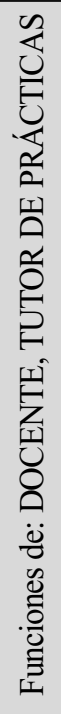 & 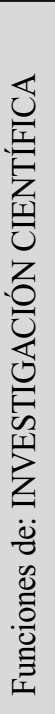 & 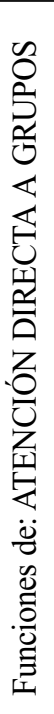 & 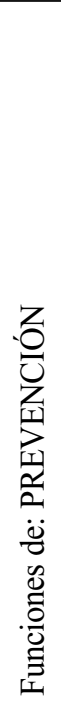 & 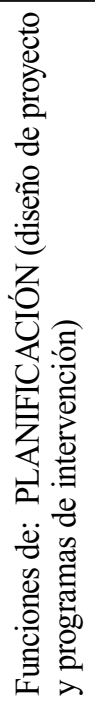 & 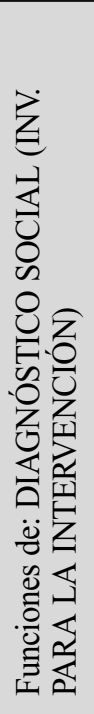 & 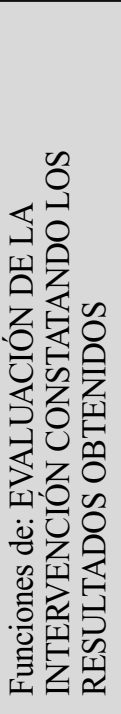 & 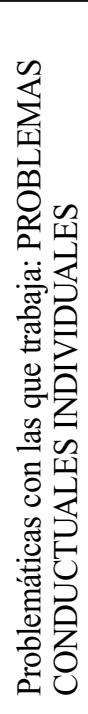 & 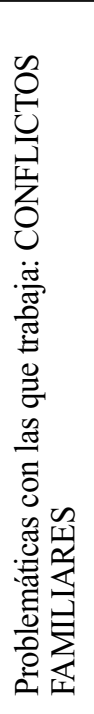 & 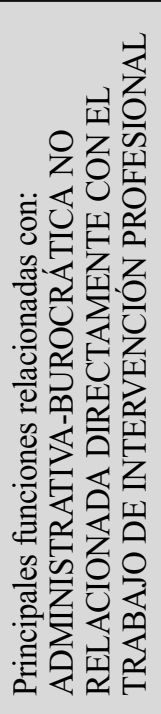 \\
\hline
\end{tabular}




\begin{tabular}{|l|r|r|}
\hline \multicolumn{1}{|c|}{ Tipologías } & N & \% \\
\hline Tipo 10. Profesionales que trabajan en intervención directa & 97 & 13,8 \\
Tipo 2. Profesionales que trabajan con necesidades sociales & 90 & 12,8 \\
Tipo 6. Profesionales que trabajan en salud y dependencia & 87 & 12,4 \\
Tipo 8. Profesionales que trabajan en atención primaria específica & 84 & 12,0 \\
Tipo 12. Profesionales polivalentes y burocráticos & 70 & 10,0 \\
Tipo 3. Profesionales de intervención socioeducativa con familia e infancia/adolescencia & 53 & 7,5 \\
Tipo 9. Profesionales que trabajan en inserción e integración social & 45 & 6,4 \\
Tipo 11. Profesionales que trabajan en atención a la mujer & 43 & 6,1 \\
Tipo 5. Profesionales que trabajan con inmigración y/o refugiados & 40 & 5,7 \\
Tipo 1. Profesionales que trabajan con conductas socialmente desviadas & 38 & 5,4 \\
Tipo 7. Profesionales que trabajan en gestión y planificación de Servicios Sociales & 37 & 5,2 \\
Tipo 4. Profesionales que trabajan como docentes e investigadores & 16 & 2,2 \\
\hline Total & $\mathbf{7 0 0}$ & $\mathbf{1 0 0}$ \\
\hline
\end{tabular}

Tabla 2. Distribución de las tipologías obtenidas por orden de importancia.

Fuente: Elaboración propia (Grupo Efimec).

sea demasiado grande. Los datos del presente análisis cumplen estos requisitos. También realizamos un análisis de varianza con el fin de conocer hasta qué punto cada uno de los factores permite una diferenciación significativa de los individuos de cada conglomerado (véase Anexo 2). El resultado (véase Tabla 2) muestra que los factores elegidos producen diferencias significativas en la concreción de los doce conglomerados.

Como técnica de agrupamiento se ha elegido la no jerárquica (K-means) y los resultados obtenidos han sido validados mediante análisis discriminante stepwise (bondad de la clasificación obtenida). Dicho análisis señala que clasifica correctamente el 96,8 por ciento de los casos (véase Anexo 3). La capacidad discriminante del modelo no ha hecho necesario eliminar ningún ítem del modelo. De la realización de dicho estudio emergen doce grupos característicos:

Tipo 1. Profesionales que trabajan con conductas socialmente desviadas $(5,4$ por ciento; $\mathbf{N}=\mathbf{3 8}$ )

El porcentaje de profesionales que se integran en esta tipología representa el 5,4 por ciento del conjunto de la muestra. La desviación social es el comportamiento que los miembros de una sociedad identifican como una violación de sus normas. Por lo tanto, las conductas desviadas representan el distanciamiento de la norma y ocurre cuando un individuo o un grupo no se comporta en consonancia con los patrones definidos socialmente. Es el caso de la delincuencia, el consumo de drogas, la ludopatía, la prostitución o el alcoholismo. Este perfil profesional viene claramente delimitado por la posición en torno al ámbito de intervención en el que desempeñan su trabajo profesional, relacionado mayoritariamente con el trabajo con individuos y grupos que presentan características de conductas desviadas (drogadicción, alcoholismo, ludopatía, reclusos). La posición factorial es muy fuerte y delimita claramente la tipología. No obstante, también aparecen otros factores cuya temática se encuentra claramente relacionada como la intervención en problemas conductuales y conflictos familiares y en temas de inserción social.

Otro aspecto relevante a destacar en torno a este grupo es la posición factorial referida a las funciones que desempeñan. Destacan por ser profesionales que trabajan en entidades o en servicios donde realizan funciones muy relacionadas con la intervención profesional directa. Se registran posiciones factoriales positivas en torno al trabajo de carácter comunitario, desarrollando programas y proyectos de intervención, así como programas e intervenciones de tipo preventivo. Igualmente llevan a cabo funciones de diagnóstico y de evaluación. Este aspecto, unido a una posición factorial negativa en torno a un desempeño profesional burocrático, retrata un perfil profesional altamente centrado en la intervención directa.

Finalmente, anotar que son profesionales abiertos a la colaboración docente e investigado- 


\section{Tipo 1}

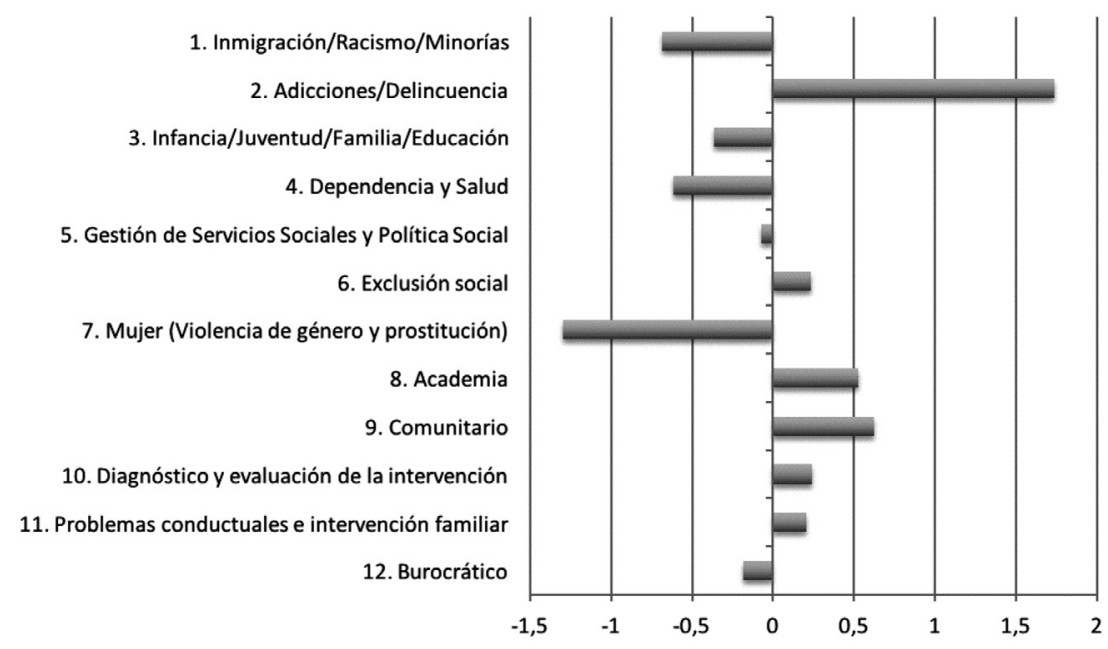

Gráfico 1. Profesionales que trabajan con conductas socialmente desviadas.

ra. El Libro Blanco del Trabajo Social (Vázquez, 2004) sitúa a estos profesionales en servicios de atención (información, prevención, diagnóstico y tratamiento) a las drogodependencias, comunidades terapéuticas, centros de rehabilitación y de reinserción social y laboral.

Mayoritariamente son profesionales que trabajan en entidades de salud (64,3 por ciento) y/o en los servicios sociales especializados (17,9 por ciento). Es significativo que lo hagan de forma mayoritaria en entidades externas al servicio público: entidades concertadas ( 46,4 por ciento) y entidades privadas $(21,4$ por ciento). Destaca que se trata de profesionales que se encuentran sobrerrepresentados entre los profesionales que tienen un alto grado de experiencia laboral (el 42,9 por ciento posee más de 16 años de experiencia).

Tipo 2. Profesionales que trabajan con necesidades sociales $(12,8$ por ciento; $N=90)$

El concepto de necesidades sociales alude a aquellas carencias determinantes para el desarrollo de las personas que originan que ciertos individuos y grupos sociales sufran procesos de aislamiento social de un individuo o de un grupo social respecto de las posibilidades laborales, económicas, culturales, de vivienda, de alojamiento, etc., de las que disfrutan otros en sus mismos contextos y que se pueden convertir en elementos potenciales de desarrollo de la exclusión social. El trabajo con este tipo de necesida- des abarca una recuperación individual que se encuentra socialmente condicionada por el entorno social, lo cual conlleva un trabajo bidireccional persona-entorno.

La tipología de profesionales que se representa en este conglomerado trabaja precisamente con estas temáticas de necesidad. Las posiciones factoriales revelan un alto grado de trabajo con problemáticas de desempleo, de vivienda y económicas. Trabajan con personas y colectivos sociales que precisan atención con el fin de potenciar su autonomía, su desenvolvimiento social y su participación (como es el caso de la mujer). Por lo tanto, no es de extrañar que aparezcan en este perfil profesionales cuyas funciones obtengan puntajes factoriales elevados en aspectos como la intervención con grupos y el desarrollo de programas y proyectos de intervención y de prevención. El porcentaje de profesionales que se integra dentro de esta tipología representa el 12,8 por ciento del conjunto de la muestra $(\mathrm{N}=90)$.

Si observamos sus características socio-profesionales, observamos que se trata de profesionales que mayoritariamente realizan su trabajo en entidades como los Servicios Sociales generales (45,3 por ciento) y en los Servicios Sociales especializados ( 37,5 por ciento). Mayoritariamente ubicados en la Administración Pública (73,4 por ciento). Se trata de profesionales que tienen más de seis años de experiencia laboral (entre 6 y 15 años el 48,4 por ciento). 


\section{Tipo 2}

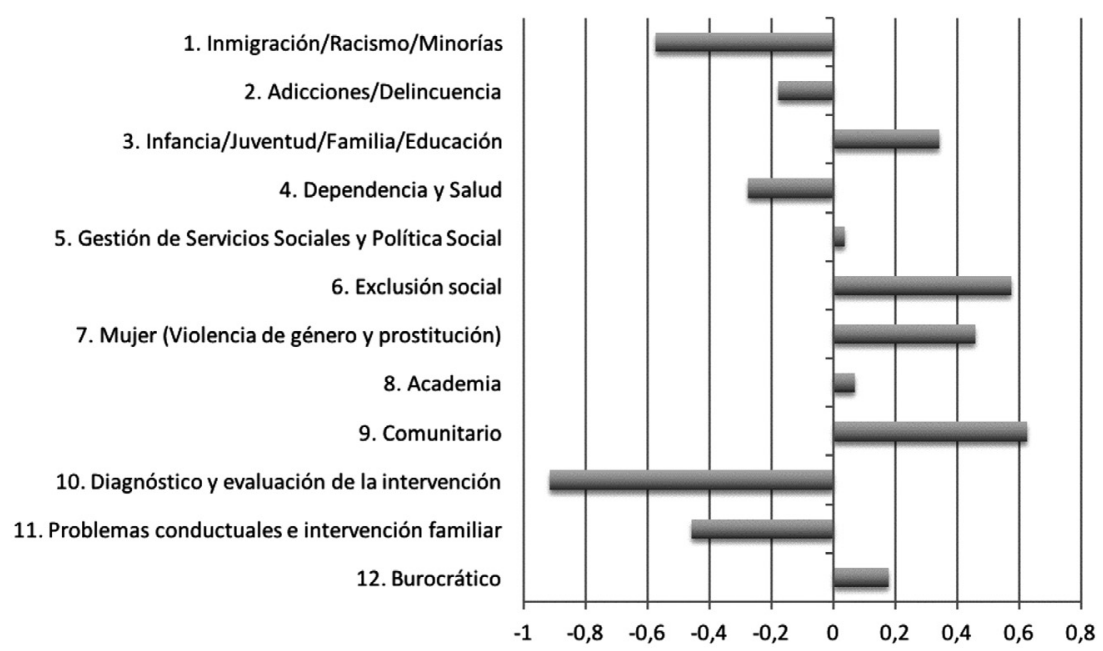

Gráfico 2. Profesionales que trabajan con necesidades sociales.

Tipo 3. Profesionales de intervención socioeducativa con familia e infancia/adolescencia (7,5 por ciento; $N=53$ )

Los resultados de la posiciones factoriales determinan que este colectivo de profesionales se caracteriza por actuar principalmente en ámbitos y problemáticas relacionadas con la intervención socioeducativa con familias, infancia y adolescencia. La familia es uno de los ámbitos clásicos de la intervención del Trabajo Social, si bien en los últimos años, debido a las presiones, demandas y cambios motivados por los complejos cambios sociales en los que nos encontramos, la familia se ha convertido en un ámbito de intervención especialmente requerido. Como señala Giddens, «de todos los cambios que ocurren en el mundo, ninguno supera en importancia a los que tienen lugar en nuestra vida privada, en la sexualidad, las relaciones, el matrimonio y la familia» (Giddens, 1999 , p. 85). Unido a la intervención familiar se encuentran la intervención con la infancia y la adolescencia. Aparecen, como líneas de intervención para el Trabajo Social, la intervención con familias que atraviesan dificultades en las relaciones entre sus miembros (maltrato, dificultades de comunicación, dificultades en la relación de pareja, dificultades en el proceso educativo y desarrollo de los hijos, crisis familiar) y con familias en situación de riesgo social, infancia y juventud (detección, valoración e intervención ante situaciones de desprotección de menores, acceso a prestaciones sociales, infancia en riesgo social).
Resulta coherente que aparezcan los problemas conductuales y los conflictos familiares como problemáticas objeto de intervención, con una posición factorial muy relevante y destacable. Se trata de profesionales que realizan funciones de intervención directa, donde el diagnóstico y la evaluación de la intervención se convierten en elementos importantes de su acción a tenor de la posición factorial obtenida. El factor burocrático, aunque esté presente, es mínimamente negativo, apuntando a no ser demasiado determinante en su acción profesional diaria.

El Libro Blanco del Trabajo Social (Vázquez, 2004) sitúa la acción de este perfil profesional en torno a servicios de diagnóstico y tratamiento para la protección de la infancia y soporte a la familia, acogimiento familiar y adopción, centros de acogida, centros residenciales y centros abiertos. Todos ellos son Servicios Sociales especializados (55,3 por ciento) donde encontramos el grueso de este perfil profesional, si bien el 23,7 por ciento se encuentra incluido en centros educativos.

El porcentaje de profesionales que se integra en esta tipología representa el 7,5 por ciento del conjunto de la muestra. Los datos indican que trabajan mayoritariamente en la Administración Pública $(68,4$ por ciento), aunque también lo hacen en menor proporción en entidades concertadas $(15,8$ por ciento) y en entidades privadas ( 15,8 por ciento). 


\section{Tipo 3}

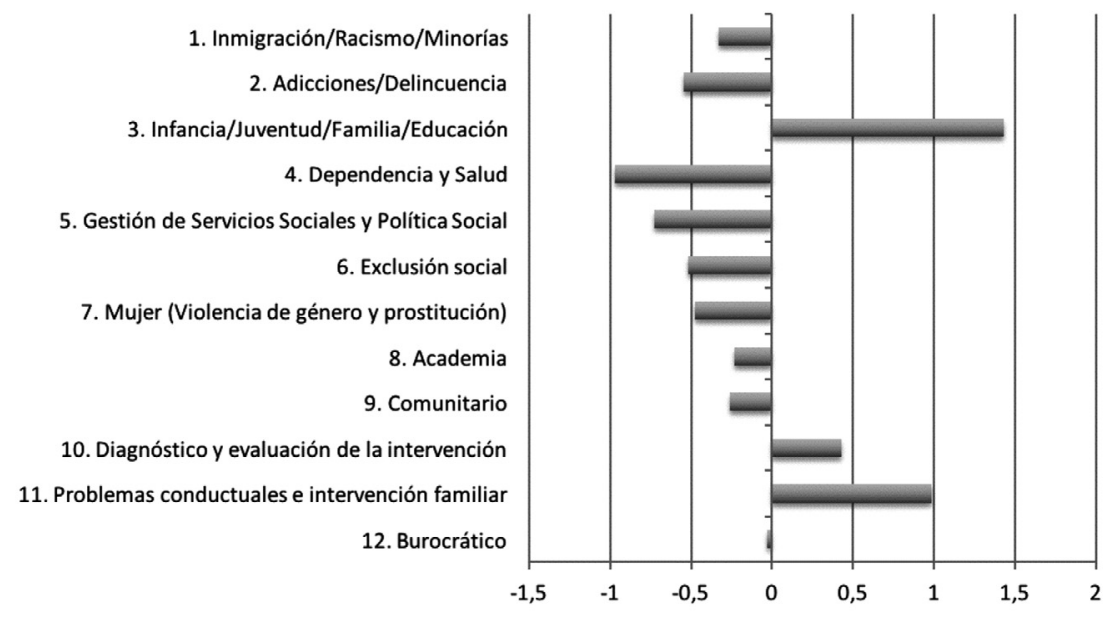

Gráfico 3. Profesionales de intervención socioeducativa con familia e infancia/adolescencia.

En cuanto a la caracterización sociodemográfica, son mayoritariamente profesionales menores de 40 años, con un nivel de experiencia profesional muy similar al observado para la media del conjunto profesional.

Tipo 4. Profesionales que trabajan como docentes e investigadores $(2,5$ por ciento; $N=16)$ Una de las funciones, que recoge la profesión del Trabajo Social como propia, es la dedicación a labores docentes, ya sean de carácter universitario o de formación continua, y a la investigación.
Es muy clara la ubicación factorial de los profesionales de este ámbito, ya que tan solo poseen una posición factorial positiva en este factor (con excepción de la intervención en problemas conductuales y conflictos familiares, donde es mínima aunque positiva). En el Libro Blanco se determina este perfil profesional como el dedicado a la «Formación y asesoramiento técnico, formación de estudiantes de trabajo social, formación permanente y soporte técnico» (p. 143). Dentro de esta función docente encontramos la impartición de enseñanzas teóricas y prácticas de Traba-

\section{Tipo 4}

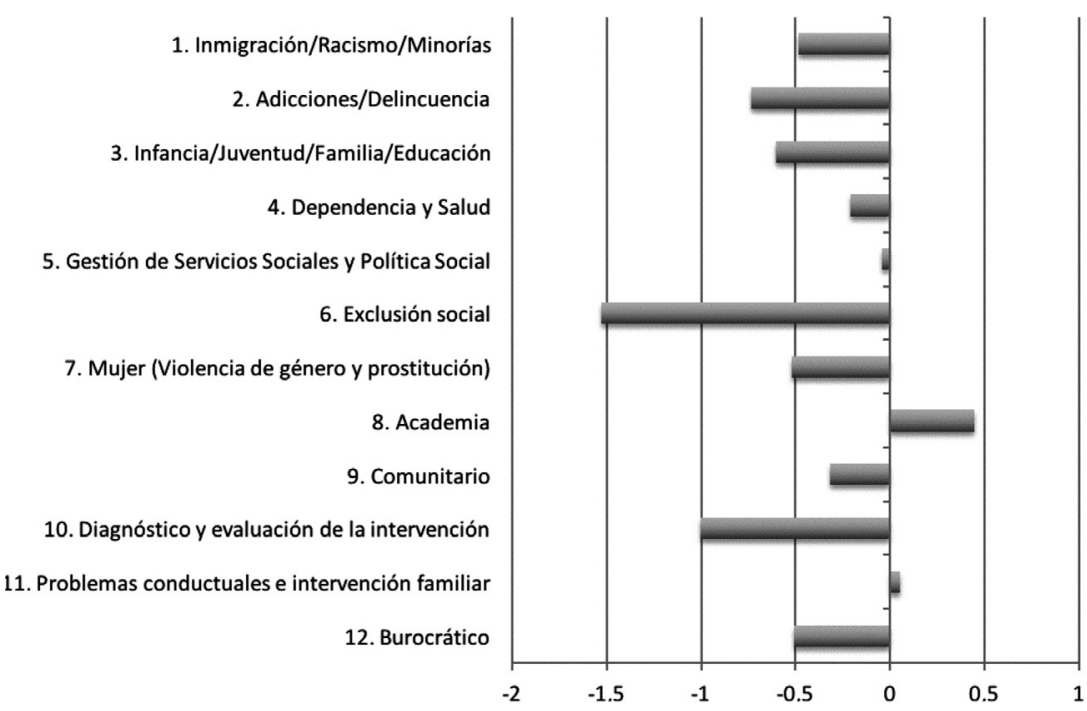

Gráfico 4. Profesionales que trabajan como docentes e investigadores. 
jo Social y de Servicios Sociales tanto en las propias escuelas de Trabajo Social como en otros ámbitos académicos.

El porcentaje de profesionales que se integra dentro de esta tipología representa el 2,5 por ciento del conjunto de la muestra y su caracterización socio-profesional nos indica que se trata de profesionales que mayoritariamente desempeñan su labor en la Administración Pública (57,1 por ciento), aunque estén por debajo de la media ( 69,8 por ciento), en entidades de los servicios especializados (57,1 por ciento) y en dependencia (17,9 por ciento). La edad y la experiencia laboral de estos profesionales están sobrerrepresentadas con respecto a la media de profesionales con más de 41 años y con una experiencia laboral superior a los 16 años.

Tipo 5. Profesionales que trabajan con inmigración y/o refugiados $(5,7$ por ciento; $N=40)$ Los resultados factoriales obtenidos nos informan de que se trata de un colectivo de profesionales que se caracteriza por poseer los factores relacionados con la intervención en el área de inmigración y la marginación y con el trabajo con problemáticas relacionadas con el racismo, minorías y alojamiento. Este campo de intervención profesional del Trabajo Social ha observado un crecimiento exponencial durante los últimos años debido al incremento de las migraciones. Este crecimiento se puede observar en el aumento de servicios dentro de las instituciones sociales, en la creación y el desarrollo de organizaciones y asociaciones para la atención específica a estos colectivos y en el aumento de recursos y dotaciones presupuestarias para financiar proyectos y programas destinados a estos grupos. El conjunto de profesionales que intervienen exclusivamente en este ámbito representan casi el 5 por ciento de los trabajadores sociales encuestados (4,7 por ciento).

Los datos factoriales nos indican que en este conglomerado poseen una importancia relevante las funciones profesionales orientadas a la prevención, planificación y a la atención de grupos en coherencia con el abordaje profesional que se lleva a cabo en torno a estas problemáticas, donde el abordaje profesional tiene un carácter integral, atendiendo al conjunto de problemáticas y dimensiones de integración tanto de la persona como del colectivo (dimensión intercultural). Las funciones de diagnóstico y evaluación de la intervención poseen una posición factorial positiva, aunque menos relevante que las anteriores.

La intervención profesional con estos colectivos se centra en aspectos de inserción sociolaboral, en la integración espacial y residencial, en la configuración de las relaciones de estos con las instituciones y las organizaciones sociales existentes, la interacción con la población autóctona y en los aspectos y dinámicas interculturales. En cuanto a la caracterización sociodemográfica del colectivo, cabe señalar que destacan por ser significativamente profesionales jóvenes. El 54,2 por ciento tiene entre 31 y 40 años, y el

\section{Tipo 5}

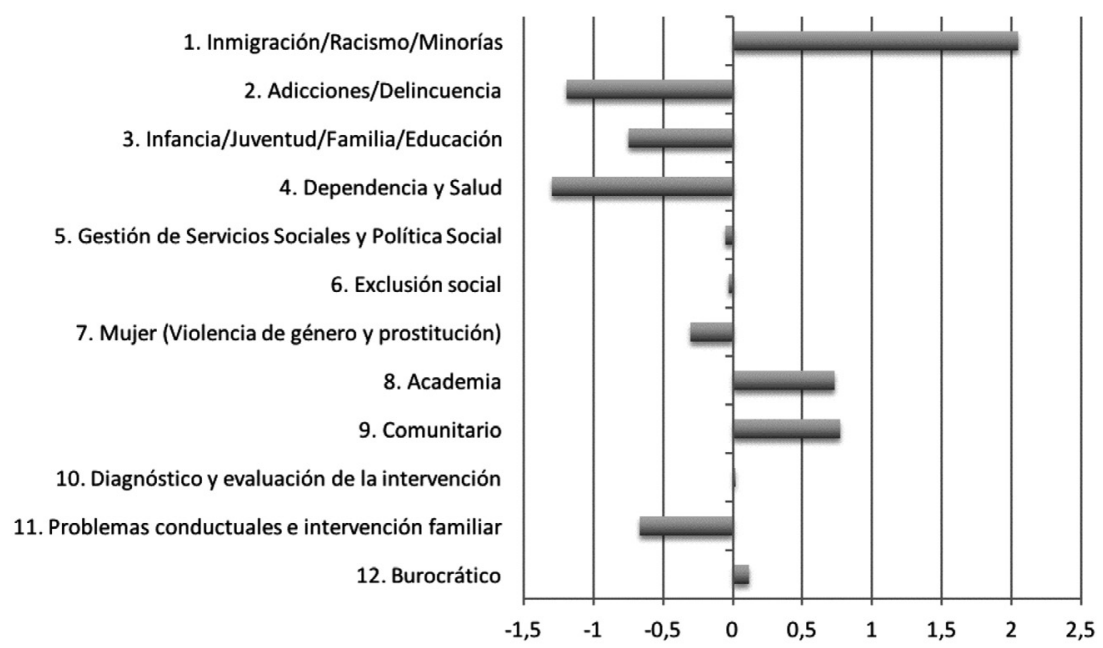

Gráfico 5. Profesionales que trabajan con inmigración y/o refugiados. 
25 por ciento menos de 30 años. En este sector se da una mayor sobrerrepresentación de los profesionales varones con respecto a la media (el 29,2 por ciento).

El 41,7 por ciento de ellos desempeñan su labor profesional mayoritariamente en el sector privado, mientras que el 12,5 por ciento lo hace en entidades concertadas y «solamente» el 29,2 por ciento en el ámbito público (la media para el conjunto es del 69,8 por ciento). Esto es explicable ya que, desde comienzos de los años noventa, la acción social con la inmigración ha sido desarrollada y canalizada a través de organizaciones sociales y entidades solidarias, aunque en los últimos años ha aumentado la presencia del sector público (Servicios Sociales). Su actividad se integra en entidades de los Servicios Sociales especializados (78,3 por ciento) y en entidades sociales del Tercer Sector (17,4 por ciento).

Tipo 6. Profesionales que trabajan en salud y dependencia $(12,4$ por ciento; $N=87)$

En términos numéricos, es la cuarta agrupación en orden de importancia, ya que representa al 12,4 por ciento de los profesionales encuestados. Se trata de un colectivo de profesionales que esencialmente trabaja con personas con discapacidad, con personas mayores, con enfermos terminales, con enfermos psiquiátricos no institucionalizados, en salud mental y en centros de salud y hospitales.

A todos ellos les une la atención a personas que se encuentran en situación de dependencia y la promoción de su autonomía personal. Los destinatarios de su acción son personas que requieren apoyos para poder desarrollar las actividades esenciales de su vida diaria, con el fin de alcanzar una mayor autonomía personal y poder disfrutar con plenitud de sus derechos como ciudadanos. En este colectivo confluyen profesionales del ámbito sanitario, que es sin duda uno de los ámbitos clásicos de intervención del Trabajo Social, y profesionales de nuevos campos profesionales relacionados con la salud como son la dependencia y la discapacidad.

Respecto a su desempeño profesional, el estadístico factorial destaca en primer lugar la posición del factor burocrático, lo que parece informar de la existencia de una elevada carga administrativa en su trabajo diario. Ello puede ser debido a que este colectivo realiza diariamente tareas relacionadas con la valoración de usuarios y demandas en las que el componente administrativo y de gestión burocrática es intenso (por ejemplo, la Escala de Valoración Social de la Dependencia). Además de este aspecto, los datos nos informan de que las funciones de intervención profesional se desarrollan en los niveles asistencial, de gerencia, de prevención y planificación (atención a grupos), si bien en distinto grado de importancia.

La intervención en problemas conductuales y conflictos familiares ofrece una posición factorial destacable y ello es debido a que el Trabajo Social en salud, dependencia y discapacidad interviene en el plano individual, atendiendo los problemas de las personas en el nivel más básico y elemental como es la persona y su familia.

\section{Tipo 6}

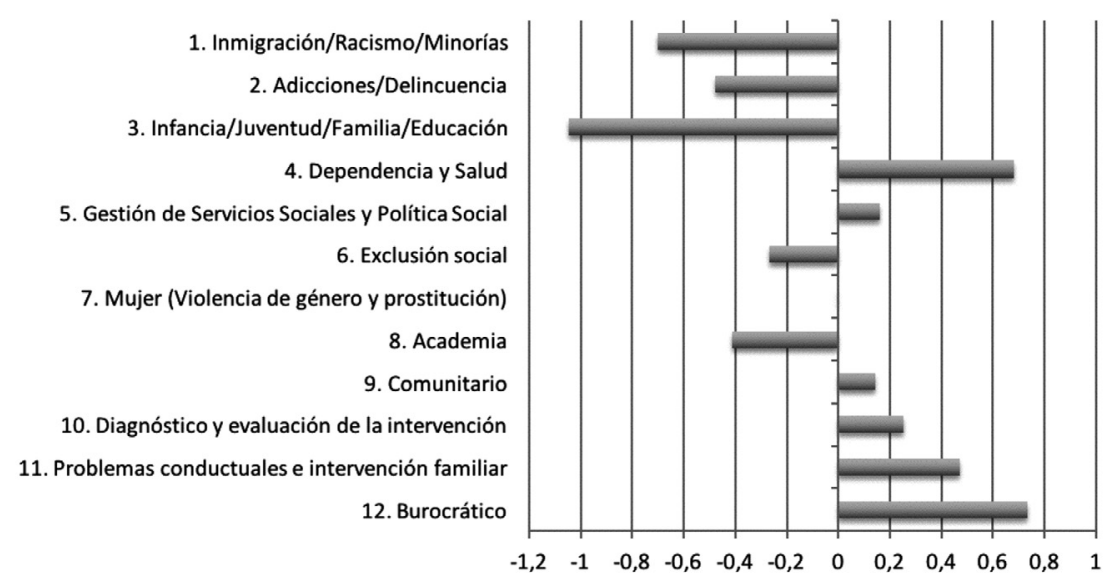

Gráfico 6. Profesionales que trabajan en salud y dependencia. 
Pero, además de ello, el trabajo de estos profesionales posee una dimensión de intervención grupal y comunitaria, evitando que la enfermedad, la discapacidad o la dependencia se conviertan en causa de disfunciones sociales que puedan agravar la situación y provocar diferentes grados de marginación social y deterioro de la salud.

En cuanto a sus características sociodemográficas, existe un alto porcentaje de profesionales que trabajan en los ámbitos privado (36,5 por ciento) o concertado (11,1 por ciento). Esto significa que esta es una tipología en la que el sector público ve recortada su influencia ocupacional. Se trata de profesionales que, conforme a lo expresado en el Libro Blanco, realizan su labor en un conjunto de asociaciones y organizaciones que trabajan con las personas que sufren enfermedades diversas y sus familias, enfermedades que afectan a los vínculos sociales y la calidad de vida de las personas (tercera edad, demencias, Alzheimer, discapacidades). Es un área profesional en el que de forma significativa destacan los servicios especializados (60,3 por ciento) y de salud (20,6 por ciento).

Son profesionales «jóvenes», en el sentido de que se ven sobrerrepresentados claramente conforme a los valores medios: el 30,2 por ciento tiene menos de 30 años y el 46 por ciento tiene entre 31 y 40 años. Esto significa que se ha convertido en un nicho laboral que durante los últimos años ha crecido en importancia.

\section{Tipo 7. Profesionales que trabajan en gestión y planificación de Servicios Sociales $(5,3$ por ciento; $N=37$ )}

Este perfil agrupa a todos aquellos profesionales que poseen una posición factorial relevante en torno a la realización de funciones de planificación estratégica de servicios de bienestar, análisis y desarrollo organizacional, gestión de servicios y equipamientos sociales y donde la intervención directa con los usuarios es negativa. Las posiciones factoriales indican que tiene gran peso todo lo que conlleve diseño y planificación estratégica, donde el diagnóstico y la evaluación también tienen importancia. El porcentaje de profesionales que se integra dentro de esta tipología representa el 5,3 por ciento del conjunto de la muestra.

El Libro Blanco los recoge como un abanico de ámbitos nuevos de actuación para los profesionales de los Servicios Sociales, debido a que los Servicios Sociales, como producto de su desarrollo y diversificación para atender tipos de personas y problemáticas diferenciadas, han visto que eran necesarios una serie de profesionales que se encargaran de planificar y gestionar mejor los mismos. En la gestión de los Servicios Sociales aparecen demandas relacionadas con la adaptación de la atención social a las nuevas demandas y necesidades de la ciudadanía, con la adopción de nuevas formas de estructurar las organizaciones y entidades de lo social, con las formas de construir y organizar el contenido téc-

\section{Tipo 7}

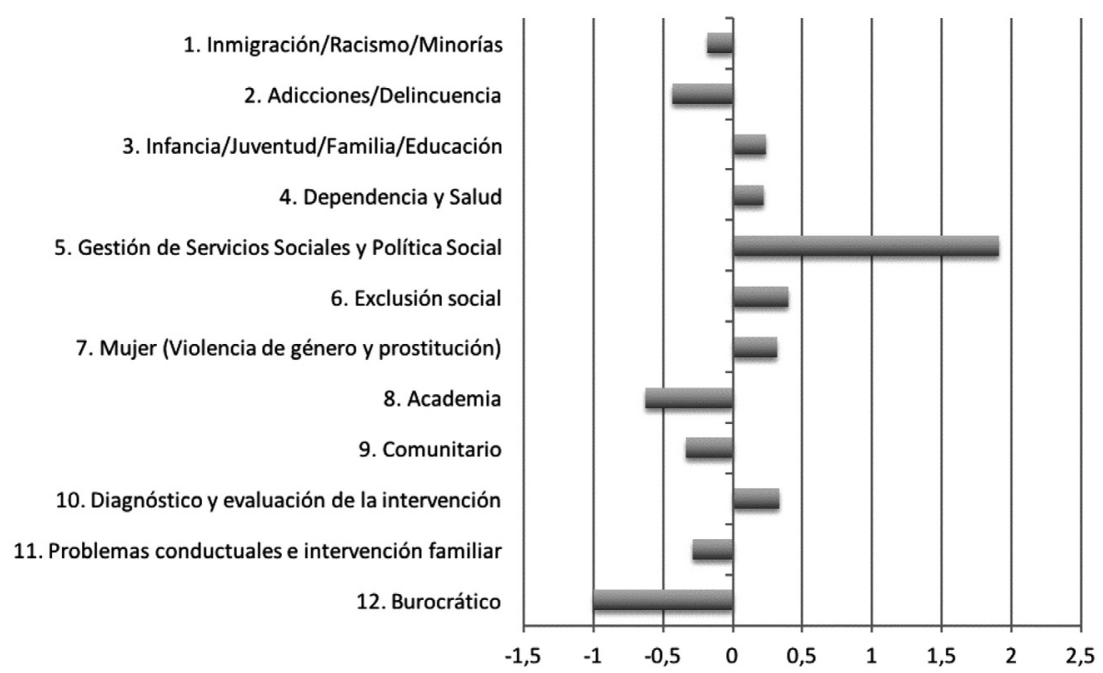

Gráfico 7. Profesionales que trabajan en gestión y planificación de Servicios Sociales. 
nico de las organizaciones, con la implantación de sistemas de evaluación y calidad de la atención social y con la gestión económica y de los recursos humanos. La emergencia de este perfil profesional y de su especificidad se puede constatar en el aumento de másteres y cursos de especialización en esta materia desarrollados durante los últimos años.

El resto de posiciones factoriales positivas observadas en este perfil tienen que ver con los ámbitos y problemáticas de intervención en los que estos profesionales se desenvuelven: familia, juventud, educación, salud y dependencia, inserción social y mujer. En este perfil son varias las características socio-profesionales que caracterizan su composición y destaca:

- Una sobrerrepresentación significativa de los varones. El 22,2 por ciento de los profesionales de este grupo lo son (frente al 11 por ciento de media), duplicando su representación.

- Son profesionales maduros. Se observa como la edad y la experiencia laboral se convierten en elementos clave para acceder a este tipo de puestos o de responsabilidades profesionales, de carácter planificador y gestor. El 63 por ciento tiene entre 41 y 50 años y el 14,8 por ciento más de 50 años.

- Son profesionales que mayoritariamente ejercen en los Servicios Sociales (59,3 por ciento) y dentro del sector de la Administración Pública $(96,3$ por ciento).

\section{Tipo 8. Profesionales que trabajan en aten- ción primaria específica $(12,0$ por ciento; $\mathbf{N}=\mathbf{8 4}$ )}

Esta tipología agrupa al 12,0 por ciento de los profesionales encuestados y representa el cuarto grupo en importancia. Se trata de un conglomerado en el que se produce una situación de posiciones factoriales positivas heterogéneas, existiendo varios factores que registran pesos similares en importancia. El estadístico informa de que se trata de profesionales que enfrentan situaciones y problemáticas de intervención diversas: inmigración, salud, dependencia, adicciones, familia, juventud y mujer.

Se trata principalmente de profesionales que desempeñan una labor dirigida a una población con desventajas personales o problemas de dependencia, orientada al tratamiento, la rehabilitación y la reinserción, que realizan su labor en el ámbito de la atención primaria, ya sea de Servicios Sociales o de Salud. Esto se justifica por la caracterización socio-profesional de este colectivo: el 42,9 por ciento de los integrantes trabajan en Servicios Sociales de atención básica y primaria, el 19,7 por ciento en Atención Primaria de Salud y el 11,5 por ciento en Salud-Hospitales.

Son profesionales cuyas acciones son las de acogida y orientación social, el acceso a prestaciones, la derivación a otros programas y sistemas de protección social, que tiene como denominador común ser la puerta de entrada al sistema de Servicios Sociales público. Este dato

\section{Tipo 8}

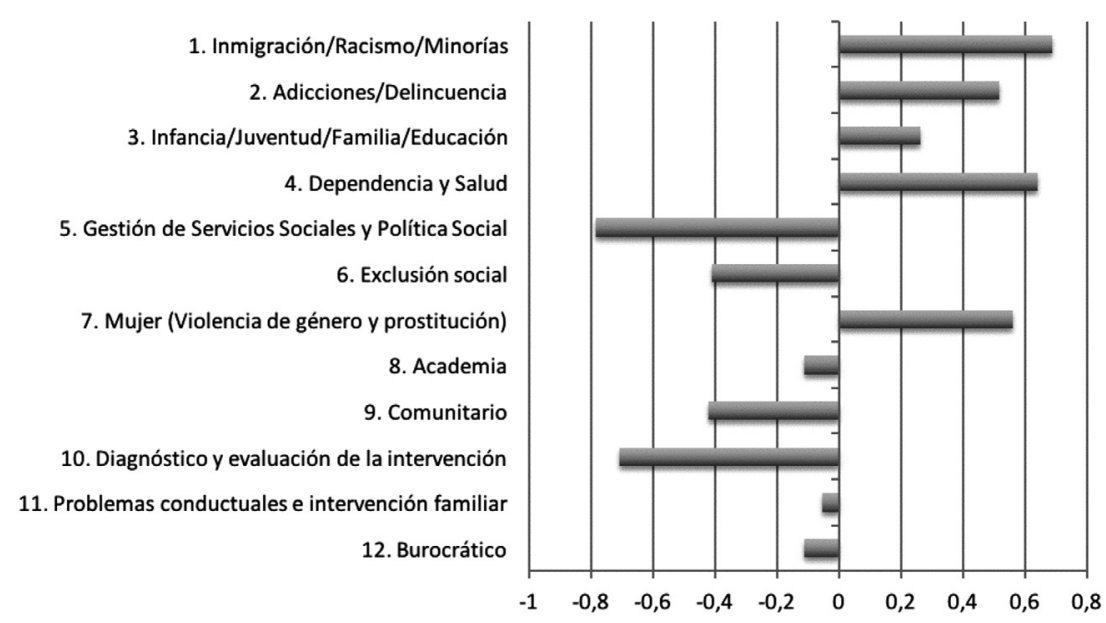

Gráfico 8. Profesionales que trabajan en atención primaria específica. 
queda corroborado por los datos estadísticos que indican que el 90,2 por ciento de los profesionales de este grupo desempeñan su labor en la Administración Pública.

Dos son los datos relativos al perfil demográfico de los profesionales que integran este perfil: una menor participación de varones que en otros perfiles $(4,9$ por ciento), una mayor presencia de profesionales maduros (sobre todo entre 41-50 años) y el dato más bajo de profesionales con edades inferiores a los 30 años (sólo representan el 6,6 por ciento de este tipo de profesionales).

\section{Tipo 9. Profesionales de la inserción e integra- ción social $(6,5$ por ciento; $N=45)$}

Es un ámbito que está integrado por profesionales que trabajan contra la exclusión social y que lo hacen a través de programas de tipo preventivo y formativo. Ello queda corroborado por las posiciones factoriales registradas en este conglomerado. Las áreas de intervención y las problemáticas tienen que ver principalmente con adicciones, inmigración, racismo, minorías y reclusos. Se trata de profesionales que trabajan con colectivos y personas que poseen diferencias muy relevantes en cuanto a sus oportunidades vitales, condiciones y calidad de vida y que se encuentran al margen del modo de vida habitual. Estos profesionales trabajan con personas que presentan dificultades e incapacidades para poder combatir y salir de la exclusión por sí mismas sin que medie una ayuda externa. Aunque homogéneo, el espacio de la exclusión presenta una diversidad de colectivos y personas que lo integran, tanto en cuanto a sus posibilidades, li- mitaciones, problemáticas, necesidades y potencialidades. Esto se refleja, como hemos apuntado antes, en las posiciones factoriales que registran determinadas problemáticas y áreas de intervención heterogéneas.

La intervención social con estos colectivos tiene muy en cuenta la dimensión del trabajo con los colectivos y con los grupos, incidiendo en la prevención (así lo revelan las posiciones factoriales observadas). Su acción radica en la perspectiva de que en la exclusión tienen relevancia los factores estructurales y la debilidad de los tejidos relacionales sobre las dificultades subjetivas, aunque estas también sean relevantes. Abordan los procesos de integración desde la recuperación personal (trabajo con problemas conductuales y conflictos familiares), desde la vinculación relacional (trabajo con grupos) y desde la inclusión en los mecanismos estructurales (prevención, planificación de proyectos y programas de intervención). El porcentaje de profesionales que se integra dentro de esta tipología representa el 6,5 por ciento del conjunto de la muestra.

Se observa que en este perfil se encuentra sobrerrepresentada la presencia de profesionales que trabajan en el Tercer Sector (el 26 por ciento). Esto ratifica el perfil, puesto que estas entidades nacen para dar respuesta a las necesidades sociales de diversos colectivos, ya sea a través de actuaciones para prevenir, paliar o revertir situaciones y procesos de marginación y exclusión social o para promover la inclusión y participación de los mismos. El área de la salud (el 30 por ciento) y de los Servicios Sociales especializa-

\section{Tipo 9}

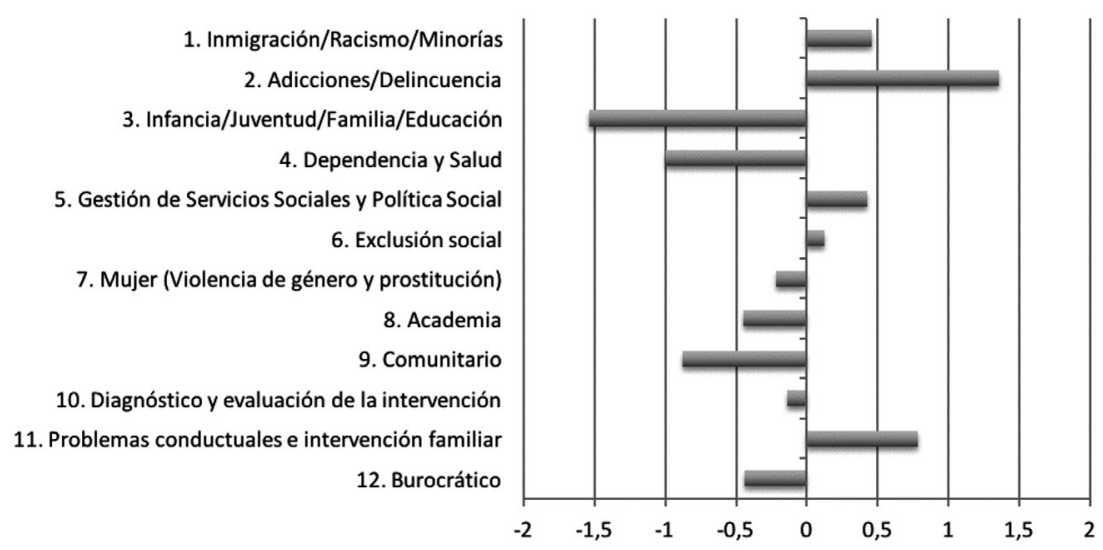

Gráfico 9. Profesionales que trabajan en inserción e integración social. 
dos (21,7 por ciento) junto con el Tercer Sector son los referentes de empleo de este tipo de perfiles profesionales. Destaca la escasa importancia que adquieren los Servicios Sociales básicos en este perfil. Estos elementos explican que los profesionales que pertenecen a entidades concertadas y privadas tengan una mayor presencia dentro de este perfil con respecto a los valores medios (el 43,5 por ciento de los profesionales trabajan en entidades que no son públicas).

Por lo que respecta a las características socioprofesionales, encontramos un alto nivel de profesionales entre los 31 y los 40 años (61 por ciento), con experiencia laboral inferior a los 15 años (78,3 por ciento).

Tipo 10. Profesionales que trabajan en intervención directa $(13,8$ por ciento; $N=97)$

Este es el conglomerado más relevante ya que representa el 13,8 por ciento de los profesionales encuestados. Se caracteriza por puntuar positivamente en tres elementos muy concretos que lo definen. Es un grupo de profesionales que prioritariamente trabaja con problemas y necesidades de carácter económico (empleo, vivienda, renta básica), de inserción social y de salud/dependencia. Además lo hace llevando a cabo funciones propias de la intervención social del Trabajo Social como el diagnóstico y la evaluación.

La finalidad del diagnóstico es aportar los elementos suficientes y necesarios para la expli- cación de la realidad social de cara a la acción y la transformación de necesidades. Así, el diagnóstico social proporciona el conocimiento de la realidad concreta, identificando carencias, necesidades, problemas y permite realizar una valoración de los mismos en orden a su prioridad. Son profesionales que realizan una valoración y clasificación de las situaciones de necesidad, sobretodo en el ámbito económico (renta de inclusión social, acceso a vivienda protegida, acceso a ayudas a la dependencia) apoyándose en un diagnóstico y en la evaluación de la acción.

Es necesario destacar que en su intervención profesional no realizan funciones de prevención, planificación, atención a grupos, ni tampoco su actividad se relaciona con la gestión, puesto que en estos factores las posiciones son claramente negativas. Igualmente significativo es el valor negativo que posee el factor burocrático, indicativo de que su labor de intervención no se ve lastrada por un exceso de trabajo administrativo.

En cuanto al perfil socio-profesional de estos profesionales, destaca que trabajan de forma mayoritaria en el ámbito público $(81,4$ por ciento), en los Servicios Sociales Básicos y de Atención Primaria (44,3 por ciento), Dependencia ( 20,0 por ciento), Discapacidad $(8,6$ por ciento) y Tercera Edad (5,7 por ciento). En este conglomerado están ligeramente sobrerrepresentadas las mujeres con respecto a la media (93 por ciento).

\section{Tipo 10}

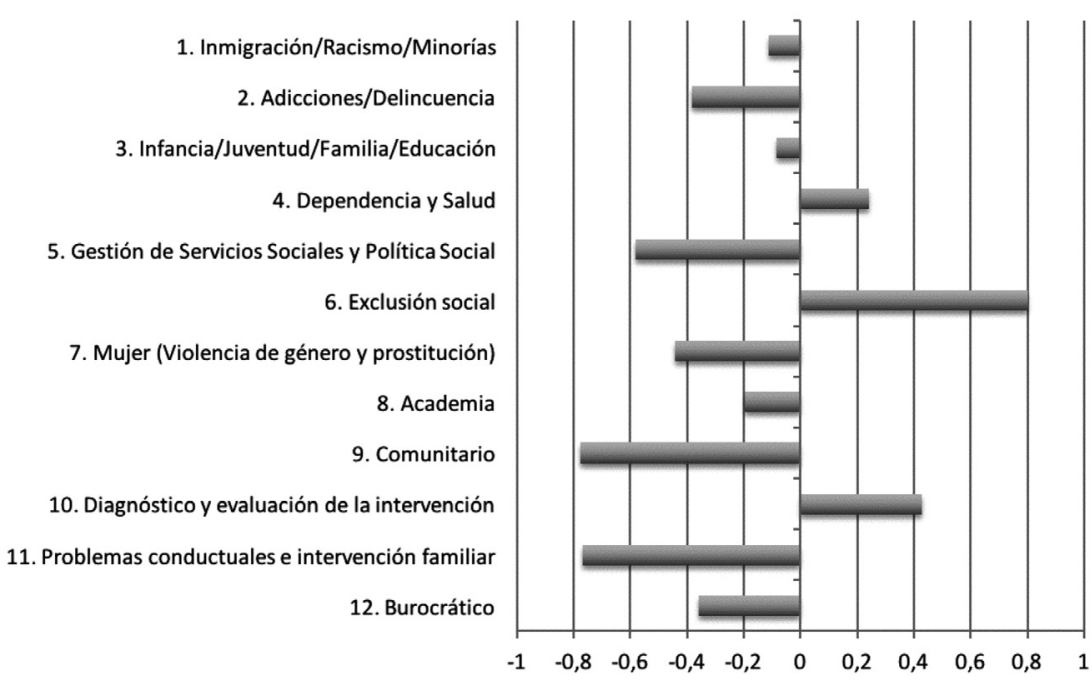

Gráfico 10. Profesionales que trabajan en intervención directa. 
Tipo 11. Profesionales que trabajan en atención a la mujer $(6,1$ por ciento; $N=43)$

Este conglomerado representa el 6,1 por ciento de los trabajadores sociales encuestados. Sus puntuaciones en los factores los caracterizan como profesionales que trabajan con problemáticas relacionadas con mujeres, violencia de género y prostitución. De forma colateral a esta temática tan clara, aparecen con posiciones factoriales más bajas la intervención en temas relacionados indirectamente con las adicciones y los temas de familia, infancia/adolescencia.

Se trata de profesionales que desempeñan su labor en servicios de información y atención psicosocial a la mujer, atención social de urgencia para mujeres víctimas de violencia doméstica, casas de acogida e inserción socio-laboral. En cuanto a la intervención, el factor relacionado con el diagnóstico y evaluación de la intervención posee una posición positiva alta. La planificación de programas y la atención a grupos ofrece un menor puntaje factorial, aunque es positivo. Lo cual significa que se lleva a cabo, aunque en menor medida. El apartado burocrático, aunque positivo, es más bien bajo, lo que nos da la medida de una cierta carga administrativa (pero no excesiva) en su trabajo.

En cuanto a las características del perfil socio-profesional, el 84 por ciento desempeña su labor profesional en el ámbito público y el 9,7 por ciento en el ámbito privado (el 3,2 por ciento en el concertado). En cuanto al área, son mayoritarios los Servicios Sociales Especializados (el 51,6 por ciento), si bien el 22,6 por ciento trabaja en los Servicios Sociales generales y el 12,9 por ciento en Salud. En los Servicios Sociales Especializados destacan obviamente aquellos que trabajan en temas de mujer ( 25,8 por ciento) y con infancia y familia (19,4 por ciento). Se trata de profesionales jóvenes, el 35,5 por ciento tiene menos de 30 años (la media es 19,9 por ciento) y un 40 por ciento tiene entre 30 y 40 años. En cuanto a la experiencia profesional, el 35,5 por ciento tiene menos de cinco años de experiencia laboral.

\section{Tipo 12. Profesionales polivalentes y burocrá- ticos $(9,9$ por ciento; $N=70)$}

El porcentaje de profesionales que se integra dentro de esta tipología representa el 9,9 por ciento del conjunto de la muestra. Tal y como se puede comprobar gráficamente, se trata de un grupo que muestra posiciones factoriales positivas en casi todos los factores analizados, a excepción de los que tienen que ver con la docencia y la atención a la mujer. Son profesionales que tratan problemáticas diversas y desempeñan todo tipo de funciones. Les une igualmente una posición factorial positiva en torno a una alta burocratización de su desempeño profesional.

Si analizamos la caracterización profesional de este colectivo, observamos que, de forma mayoritaria, desempeñan su labor profesional en la Administración Pública (91 por ciento). Además el 64 por ciento lo hace en los Servicios Sociales, el 14 por ciento en los Servicios Sociales es-

Tipo 11

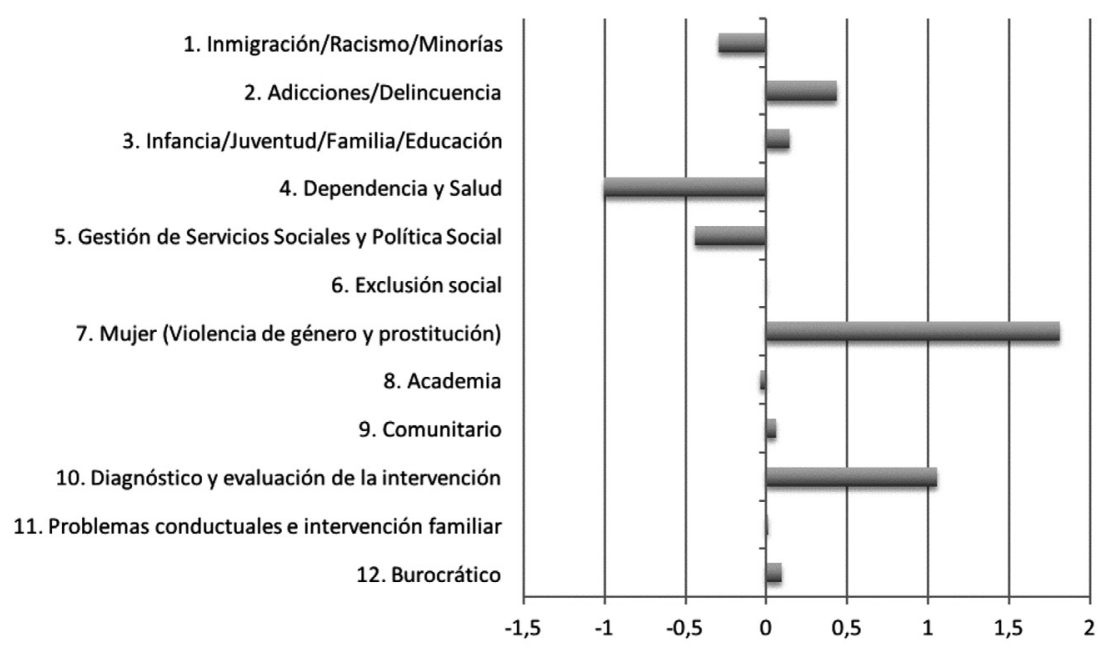

Gráfico 11. Profesionales que trabajan en atención a la mujer. 


\section{Tipo 12}

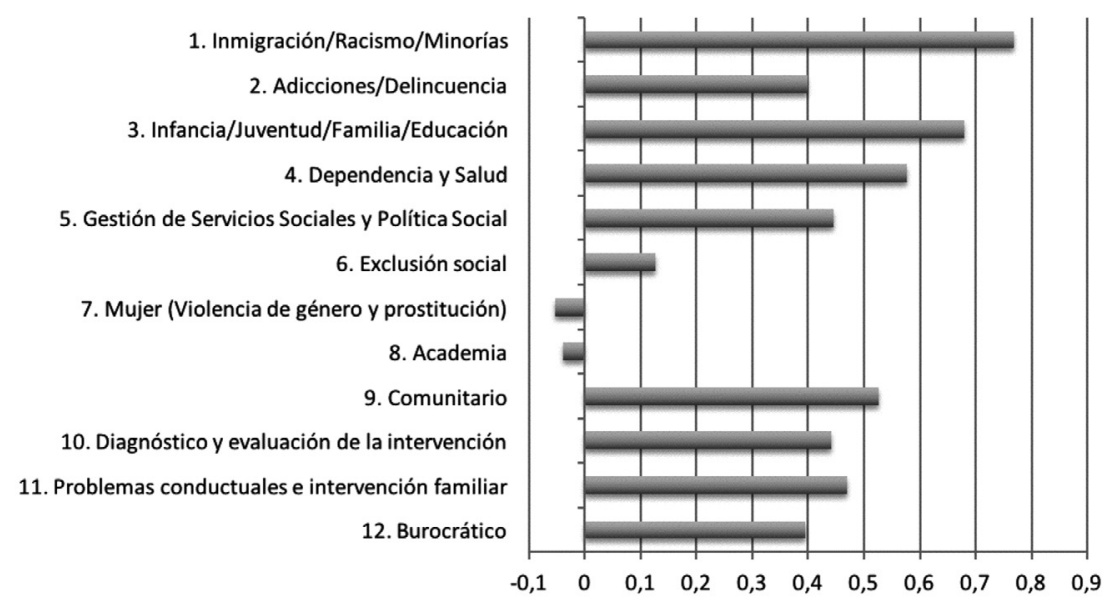

Gráfico 12. Profesionales polivalentes y burocráticos.

pecializados, el 12 por ciento en salud y un 8 por ciento en gestión de Servicios Sociales.

Esta caracterización es significativa y nos habla de que se trata de profesionales generalistas o polivalentes que trabajan preferentemente en el ámbito de la Administración, generalmente en Atención Primaria, aunque sus posiciones jerárquicas en la escala administrativa sean diferentes. Ello explica que abarquen tantas funciones, yendo desde la planificación, coordinación y diseño de políticas sociales, hasta la intervención con grupos o el diagnóstico y la evaluación de la intervención. Por tanto, como ya señalaba Sitjá (1988), se trata de profesionales multifuncionales que desarrollan sus competencias en servicios polivalentes, que son aquellos capaces de dar respuesta a una multiplicidad de necesidades sociales. Esta acepción atribuye a los Servicios Sociales Generales el carácter de «primera instancia de actuación y de contacto de la población con el sistema de Servicios Sociales, de base territorial, que desarrolla funciones de información, orientación y canalización de los usuarios hacia los servicios y recursos existentes» (Arenas, 1985 , p. 22). Tal y como señala Giménez Bertomeu (1999) esta polivalencia de los profesionales implica multifuncionalidad (funciones propias y funciones bisagra), atribuye un carácter primario a la intervención y el tipo de servicios, supone generalidad y amplitud en el objeto de intervención y significa especialización en la atención a un objeto múltiple (las necesidades de la población en general).

\section{Conclusiones}

Las profesiones evolucionan y van cambiando según la demanda ocupacional y el mercado de trabajo, lo que les atribuye una alta capacidad adaptativa. La profesión de Trabajador Social no está exenta de estas dinámicas y así lo recogen diversas publicaciones tanto nacionales como internacionales. A ello contribuyen de forma determinante las nuevas situaciones sociales que genera una sociedad postmoderna en continuo cambio (líquida) y en permanente transformación, creando nuevas necesidades y problemáticas que son objeto de análisis e intervención desde el Trabajo Social. Es incuestionable que en el Trabajo Social ante esta dinámica social, se ha originado una pluralización y diversificación cada vez más creciente de sus áreas de actuación. El principal resultado que obtenemos con el análisis que hemos llevado a cabo es demostrar la existencia de doce tipos diferentes de profesionales del Trabajo Social y ratificar lo ya expresado por Mary Richmond cuando decía que «el Trabajo Social es el arte de hacer diferentes cosas para diferentes personas y con ellas, para lograr al mismo tiempo su propia mejora de la sociedad» (Lasheras y Cortajarena, 1979, p. 172). Los trabajadores sociales trabajan de forma diferente, realizan funciones distintas, con individuos y grupos heterogéneos, trabajan con problemáticas variadas y lo hacen en diversos ámbitos de intervención.

Podríamos señalar que, desde una perspectiva interaccionista, este estudio constata que la profe- 
sión del Trabajo Social se encuentra en movimiento de desestructuración y estructuración de segmentos profesionales, en continuo dinamismo, generando nuevos subsistemas profesionales caracterizados cada uno de ellos por elementos que los definen y caracterizan fuertemente. En la investigación hemos constatado que actúan como elementos caracterizadores los ámbitos de intervención, las funciones que realizan y las problemáticas cotidianas con las que trabajan. Ahora bien, pese a dicha diferenciación y especialización en torno a diferentes subsistemas o tipos profesionales, todos ellos se reconocen dentro de la profesión y como profesionales del Trabajo Social. Existe, por lo tanto, una tensión entre la unidad y la pluralidad del perfil profesional, propia de la teoría de la complejidad.

El perfil profesional hace referencia al conjunto de capacidades y competencias que identifican la formación de una persona para asumir en condiciones óptimas las responsabilidades propias del desarrollo de sus funciones y las tareas de una determinada profesión. Sin duda, conocer estos perfiles puede servir de elemento de reflexión y de contraste, ya que es el primer estudio de estas características realizado en España.

Los resultados arrojan algunos datos interesantes para esta reflexión. Cabe destacar, por ejemplo, una constante histórica en el ejercicio profesional: la burocratización y sus consecuencias en la intervención social. Histórica porque la propia Mary Richmond ya aludía a que la sobrecarga de trabajo impedía ejercer la intervención social de modo adecuado (Richmond, 1977, p. 133). La burocratización sigue siendo una de las mayores preocupaciones de los profesionales del Trabajo Social (Guillén, 1993; Banks, 1997; Salcedo, 2001), ya que en este contexto, los profesionales se caracterizan por «su escasa consideración del usuario como sujeto agente que puede intervenir sobre su propia problemática» (Cañedo, 2011, p. 149).

En estos contextos altamente burocratizados, la intervención social se vacía del contenido que la caracteriza. Las más recientes investigaciones en nuestro país señalan que a mayor burocratización, menor sensibilidad ética y actitud crítica o autocrítica poseerán los profesionales del Trabajo Social. Prevalecen la operatividad sobre la reflexión (Idareta y Ballestero, 2013), así como las obligaciones como empleado sobre las obligaciones como profesional (Salcedo, 2001), dando lugar a profesionales más defensivos y menos reflexivos (Banks, 1997).

La alta burocratización preocupa desde los comienzos porque origina sobrecarga de trabajo, que deriva, por una parte, en una intervención social rutinaria, monótona, reiterativa, impersonal y despersonalizante (Vázquez, 2008); y, por otra, en un trato excesivamente racional, que tiende a tornar a los profesionales en insensibles $\mathrm{y}$ acríticos, reduciendo al usuario a un número, una función o un objeto (Salcedo, 2001). La alta burocratización impide o resta tiempo para el encuentro real con el usuario, dando lugar a una relación distante y objetivante.

Constatar que el 10 por ciento de los profesionales conforman la tipología de polivalentes y burocráticos, con un factor burocrático-administrativo tan alto, debe darnos motivos para la reflexión. El hecho de que sea el quinto perfil más significativo de doce (70 profesionales de 700), ¿nos podría llevar a preguntarnos si estamos asistiendo a una devaluación de la esencia del Trabajo Social?

Pero los datos nos ofrecen una visión del Trabajo Social como una profesión posmoderna, propia de su tiempo, al mostrarnos un comportamiento ambivalente. Frente a la burocratización, emerge con fuerza en el otro extremo y como cara de la misma moneda, la importancia de la intervención directa. En el análisis de datos realizado, hemos podido observar que en la mayor parte de las tipologías, a la hora de concretar los factores que determinaban la identidad y caracterización de cada tipo, tienen más peso los ámbitos y las problemáticas en los que se interviene que las funciones que se desempeñan. Sin embargo, es significativo que sean los profesionales cuyo estandarte diferenciador es la intervención directa, aquellos que representen el colectivo más importante dentro de la segmentación analizada, representando a un 13,8 por ciento de los profesionales. Esta tensión entre ambas formas de entender y ejercer el Trabajo Social, refleja lo que desde un punto de vista luhmaniano sería la tensión entre el doble mandato que la sociedad posmoderna propone al Trabajo Social. Por un lado el trabajador social debe ejercer su profesión bajo el estandarte de la defensa de la dignidad de la persona y de la intervención directa por y para la lucha de los derechos de los usuarios interviniendo directamente con ellos con el fin de proporcionar justicia social, y por otro, tiene el encargo de evitar disfuncionalidades y de ayudar a la legitimación del orden social es- 
tablecido estando sometido a las dinámicas sistémicas del poder y de la burocracia.

El resto de datos nos hablan de una profesión en la que pesan con fuerza los tipos de profesionales orientados a superar disfunciones sistémicas tales como las necesidades sociales $(12,88$ por ciento), la inserción e integración social $(6,4$ por ciento) y conductas socialmente desviadas (5,4 por ciento). Igualmente nos señalan la relevancia que determinados tipos profesionales están adquiriendo sobre otros tipos, a priori, más clásicos del Trabajo Social, como es el caso de los trabajadores sociales que trabajan en la aten- ción a la mujer $(6,1$ por ciento) y/o que trabajan con inmigración/refugiados (5,7 por ciento).

Los datos señalan que se continúa exigiendo que el profesional del Trabajo Social se adapte a circunstancias muy particulares en diferentes ámbitos, con diferentes funciones y diversas problemáticas, cuya observación continuada puede ser interesante para conocer hacia donde evoluciona la profesión y el objeto de su intervención. El conocimiento de los nuevos retos y espacios de desarrollo profesional visualizados a través de tipologías pueden ser elementos de reflexión para los integrantes de esta profesión.

\section{Referencias bibliográficas}

Ain, E.J. (2001). Ethical dilemmas of New York City Social Workers. (Tesis inédita), Yeshiva University. Arenas, J. (1985). Política social y servicios sociales. Madrid: Marsiega.

Banks, S. (1997). Ética y valores en el Trabajo Social. Barcelona: Paidós.

Cañedo, M. (2011). ¿Y esto a quién se lo cuento, al ayuntamiento?: trabajadores sociales entre la vocación y la burocracia. Un análisis antropológico del modelo de intervención de los Servicios Sociales a partir de la etnografía de una red asistencial madrileña. Cuadernos de Trabajo Social, 24, $135-153$.

Carballeda, A.J.M. (2010). Problemáticas sociales complejas y políticas públicas. Revista CS, 1, 261272. doi: $10.18046 /$ recs.i1.409

Fernández, T. (2009). Fundamentos del Trabajo Social. Madrid: Alianza Editorial.

Giddens, A. (1999). Un mundo desbocado. Los efectos de la tradición en nuestras vidas. Madrid: Taurus.

Giménez-Bertomeu, V. M. (1999). Polivalencia versus especialización: aproximaciones a un modelo saludable de intervención primaria. Alternativas: cuadernos de trabajo social, 7, 117-133.

Guillén-Sádaba, M. E. (1993). La burocratización del trabajo social en intervención social. Cuadernos de Trabajo Social, 6, 181-193.

Hernández, J. (2004). Trabajo Social en la Posmodernidad. Zaragoza: Certeza.

Idareta, F. y Ballestero, A. (2013). Ética, paternalismo y burocracia en Trabajo Social. Portularia: Revista de Trabajo Social, 13, 27-35.

Kim, J. y Mueller, Ch.W. (1978). Introduction to factor analysis : what it is and how to do it. California: Sage Publications

Lasheras, P. y Cortajarena, E. (1979). Introducción al bienestar social. Madrid: Federación Española de Asociaciones de Asistentes Sociales.

Martínez-Ramos, E. (1984). Aspectos teóricos del Análisis de Cluster y aplicación a la caracterización del electorado potencial de un partido. En Introducción a las técnicas de análisis multivariable aplicadas a las ciencias sociales. Madrid: CIS.

Richmond, M. (1977). Caso Social Individual. Buenos Aires: Humanitas.

Salazar, M. C. (2006). El proceso de profesionalización del trabajo social. Trabajo Social, 8, 27-36.

Salcedo-Megales, D. (2001). La rebelión ética: principios del Trabajo Social en el ámbito de la salud mental. Trabajo social y salud, 40, 15-42.

Sitjà, M. (1988). Terminologia dels assistents socials. Barcelona: Co-legi Oficial de Diplomats en Treball Social i Assistents Socials de Catalunya.

Uriz, M.J., Ballestero, A. y Urien, B. (2007). Dilemas éticos en la intervención social: una perspectiva profesional desde el trabajo social. Zaragoza: Mira Editores.

Vázquez, O. (2008). Los instrumentos de evaluación. En T. Fernández (ed.), Trabajo Social con casos (pp. 221-250). Madrid: Alianza Editorial.

Vázquez, O. (Coord.) (2004). Libro Blanco. Título de Grado en Trabajo Social. Madrid: ANECA.

Webb, S. (2015). Professional identity and social work. Academia.edu, 0, pp. 1-23. Recuperado de https://www.academia.edu/11047417/Professional_Identity_and_Social_Work 


\begin{tabular}{|c|c|c|c|c|c|c|c|c|c|}
\hline \multirow[b]{2}{*}{ Componente } & \multicolumn{3}{|c|}{ Autovalores iniciales } & \multicolumn{3}{|c|}{$\begin{array}{l}\text { Sumas de extracción } \\
\text { de cargas al cuadrado }\end{array}$} & \multicolumn{3}{|c|}{$\begin{array}{l}\text { Sumas de rotación } \\
\text { de cargas al cuadrado }\end{array}$} \\
\hline & Total & $\begin{array}{c}\text { Tanto } \\
\text { por ciento } \\
\text { de varianza }\end{array}$ & $\begin{array}{c}\text { Tanto } \\
\text { por ciento } \\
\text { acumulado }\end{array}$ & Total & $\begin{array}{c}\text { Tanto } \\
\text { por ciento } \\
\text { de varianza }\end{array}$ & $\begin{array}{c}\text { Tanto } \\
\text { por ciento } \\
\text { acumulado }\end{array}$ & Total & $\begin{array}{c}\text { Tanto } \\
\text { por ciento } \\
\text { de varianza }\end{array}$ & $\begin{array}{c}\text { Tanto } \\
\text { por ciento } \\
\text { acumulado }\end{array}$ \\
\hline 1 & 10,332 & 21,086 & 21,086 & 10,332 & 21,086 & 21,086 & 4,807 & 9,810 & 9,810 \\
\hline 2 & 4,534 & 9,254 & 30,340 & 4,534 & 9,254 & 30,340 & 4,280 & 8,735 & 18,545 \\
\hline 3 & 3,178 & 6,486 & 36,826 & 3,178 & 6,486 & 36,826 & 3,392 & 6,922 & 25,468 \\
\hline 4 & 2,629 & 5,365 & 42,191 & 2,629 & 5,365 & 42,191 & 3,035 & 6,193 & 31,661 \\
\hline 5 & 2,024 & 4,130 & 46,321 & 2,024 & 4,130 & 46,321 & 2,752 & 5,615 & 37,277 \\
\hline 6 & 1,937 & 3,953 & 50,274 & 1,937 & 3,953 & 50,274 & 2,607 & 5,321 & 42,598 \\
\hline 7 & 1,473 & 3,007 & 53,281 & 1,473 & 3,007 & 53,281 & 2,411 & 4,921 & 47,519 \\
\hline 8 & 1,332 & 2,718 & 55,999 & 1,332 & 2,718 & 55,999 & 2,015 & 4,113 & 51,632 \\
\hline 9 & 1,293 & 2,639 & 58,638 & 1,293 & 2,639 & 58,638 & 1,961 & 4,002 & 55,634 \\
\hline 10 & 1,179 & 2,406 & 61,044 & 1,179 & 2,406 & 61,044 & 1,648 & 3,364 & 58,998 \\
\hline 11 & 1,154 & 2,355 & 63,400 & 1,154 & 2,355 & 63,400 & 1,600 & 3,265 & 62,263 \\
\hline 12 & 1,023 & 2,088 & 65,488 & 1,023 & 2,088 & 65,488 & 1,580 & 3,225 & 65,488 \\
\hline 13 & 0,966 & 1,972 & 67,460 & & & & & & \\
\hline 14 & 0,944 & 1,927 & 69,386 & & & & & & \\
\hline 15 & 0,859 & 1,754 & 71,140 & & & & & & \\
\hline 16 & 0,807 & 1,647 & 72,786 & & & & & & \\
\hline 17 & 0,783 & 1,598 & 74,385 & & & & & & \\
\hline 18 & 0,722 & 1,473 & 75,858 & & & & & & \\
\hline 19 & 0,678 & 1,383 & 77,241 & & & & & & \\
\hline 20 & 0,662 & 1,351 & 78,591 & & & & & & \\
\hline 21 & 0,633 & 1,292 & 79,884 & & & & & & \\
\hline 22 & 0,615 & 1,256 & 81,139 & & & & & & \\
\hline 23 & 0,588 & 1,200 & 82,339 & & & & & & \\
\hline 24 & 0,553 & 1,129 & 83,468 & & & & & & \\
\hline 25 & 0,537 & 1,096 & 84,564 & & & & & & \\
\hline 26 & 0,510 & 1,041 & 85,605 & & & & & & \\
\hline 27 & 0,503 & 1,027 & 86,633 & & & & & & \\
\hline 28 & 0,476 & 0,971 & 87,603 & & & & & & \\
\hline 29 & 0,454 & 0,926 & 88,529 & & & & & & \\
\hline 30 & 0,439 & 0,897 & 89,426 & & & & & & \\
\hline 31 & 0,422 & 0,861 & 90,287 & & & & & & \\
\hline 32 & 0,397 & 0,809 & 91,096 & & & & & & \\
\hline 33 & 0,383 & 0,781 & 91,877 & & & & & & \\
\hline 34 & 0,381 & 0,778 & 92,656 & & & & & & \\
\hline 35 & 0,360 & 0,736 & 93,391 & & & & & & \\
\hline 36 & 0,334 & 0,681 & 94,072 & & & & & & \\
\hline 37 & 0,326 & 0,666 & 94,738 & & & & & & \\
\hline 38 & 0,303 & 0,618 & 95,356 & & & & & & \\
\hline 39 & 0,286 & 0,584 & 95,940 & & & & & & \\
\hline 40 & 0,269 & 0,548 & 96,488 & & & & & & \\
\hline 41 & 0,252 & 0,515 & 97,002 & & & & & & \\
\hline 42 & 0,237 & 0,483 & 97,486 & & & & & & \\
\hline 43 & 0,227 & 0,462 & 97,948 & & & & & & \\
\hline 44 & 0,206 & 0,421 & 98,369 & & & & & & \\
\hline 45 & 0,199 & 0,407 & 98,776 & & & & & & \\
\hline 46 & 0,192 & 0,391 & 99,167 & & & & & & \\
\hline 47 & 0,158 & 0,322 & 99,489 & & & & & & \\
\hline 48 & 0,143 & 0,292 & 99,781 & & & & & & \\
\hline 49 & 0,107 & 0,219 & 100,000 & & & & & & \\
\hline
\end{tabular}

Anexo 1. Varianza total explicada.

Fuente: Elaboración propia (Grupo Efimec). 


\begin{tabular}{|l|r|r|}
\hline & F & Sig. \\
\hline Factor 1 & 37,087 & 0,000 \\
Factor 2 & 44,869 & 0,000 \\
Factor 3 & 47,452 & 0,000 \\
Factor 4 & 34,732 & 0,000 \\
Factor 5 & 31,547 & 0,000 \\
Factor 6 & 21,120 & 0,000 \\
Factor 7 & 32,911 & 0,000 \\
Factor 8 & 8,788 & 0,000 \\
Factor 9 & 17,638 & 0,000 \\
Factor 10 & 25,666 & 0,000 \\
Factor 11 & 18,796 & 0,000 \\
Factor 12 & 10,094 & 0,000 \\
\hline
\end{tabular}

Anexo 2. Diferencias significativas de los factores en cada conglomerado (Análisis de Varianza). Fuente: Elaboración propia (Grupo Efimec).

\begin{tabular}{|c|c|c|c|c|c|c|c|c|c|c|c|c|c|c|c|}
\hline & & \multirow[b]{3}{*}{ Clúster } & \multicolumn{13}{|c|}{ Resultados de la clasificación* } \\
\hline & & & \multicolumn{13}{|c|}{ Grupo de pertenencia pronosticado } \\
\hline & & & 1 & 2 & 3 & 4 & 5 & 6 & 7 & 8 & 9 & 10 & 11 & 12 & Total \\
\hline \multirow{12}{*}{ 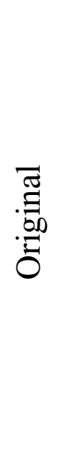 } & \multirow{12}{*}{ 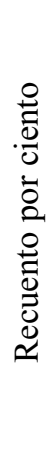 } & 1 & 96,8 & 0,0 & 0,0 & 0,0 & 0,0 & 0,0 & 0,0 & 0,0 & 3,2 & 0,0 & 0,0 & 0,0 & 100,0 \\
\hline & & 2 & 0,0 & 96,8 & 0,0 & 0,0 & 0,0 & 0,0 & 1,6 & 0,0 & 0,0 & 0,0 & 0,0 & 1,6 & 100,0 \\
\hline & & 3 & 0,0 & 0,0 & 90,2 & 0,0 & 0,0 & 0,0 & 0,0 & 2,4 & 0,0 & 0,0 & 4,9 & 2,4 & 100,0 \\
\hline & & 4 & 0,0 & 0,0 & 3,7 & 92,6 & 0,0 & 3,7 & 0,0 & 0,0 & 0,0 & 0,0 & 0,0 & 0,0 & 100,0 \\
\hline & & 5 & 0,0 & 0,0 & 0,0 & 0,0 & 100,0 & 0,0 & 0,0 & 0,0 & 0,0 & 0,0 & 0,0 & 0,0 & 100,0 \\
\hline & & 6 & 0,0 & 1,6 & 0,0 & 0,0 & 0,0 & 98,4 & 0,0 & 0,0 & 0,0 & 0,0 & 0,0 & 0,0 & 100,0 \\
\hline & & 7 & 0,0 & 0,0 & 0,0 & 3,4 & 0,0 & 0,0 & 96,6 & 0,0 & 0,0 & 0,0 & 0,0 & 0,0 & 100,0 \\
\hline & & 8 & 0,0 & 0,0 & 0,0 & 1,8 & 0,0 & 0,0 & 0,0 & 96,4 & 0,0 & 1,8 & 0,0 & 0,0 & 100,0 \\
\hline & & 9 & 0,0 & 0,0 & 0,0 & 0,0 & 0,0 & 0,0 & 0,0 & 4,5 & 95,5 & 0,0 & 0,0 & 0,0 & 100,0 \\
\hline & & 10 & 0,0 & 0,0 & 0,0 & 0,0 & 0,0 & 0,0 & 0,0 & 0,0 & 0,0 & 100,0 & 0,0 & 0,0 & 100,0 \\
\hline & & 11 & 0,0 & 0,0 & 0,0 & 0,0 & 0,0 & 0,0 & 0,0 & 0,0 & 0,0 & 0,0 & 100,0 & 0,0 & 100,0 \\
\hline & & 12 & 0,0 & 1,9 & 0,0 & 0,0 & 0,0 & 0,0 & 0,0 & 1,9 & 0,0 & 0,0 & 0,0 & 96,2 & 100,0 \\
\hline
\end{tabular}

Anexo 3. Resultados del análisis discriminante.

* Clasificados correctamente el 96,8 por ciento de los casos agrupados originales.

Fuente: Elaboración propia (Grupo Efimec). 